\title{
Effects of sixty six adolescent tobacco use cessation trials and seventeen prospective studies of self-initiated quitting
}

\author{
Sussman S \\ Institute for Health Promotion and Disease Prevention Research, University of Southern California, USA
}

\begin{abstract}
This paper provides a review of the last two and a half decades of research in adolescent and young-adult tobacco use cessation. A total of 66 tobacco cessation intervention studies - targeted or population - are reviewed. In addition, an exhaustive review is completed of adolescent self-initiated tobacco use cessation, involving 17 prospective survey studies.

Average reach and retention across the intervention studies was $61 \%$ and $78 \%$, respectively, and was higher when whole natural units were treated (e.g., classrooms), than when units created specifically for the program were treated (e.g., school-based clinics). The mean quit-rate at a three to 12-month average follow-up among the program conditions was $12 \%$, compared to approximately $7 \%$ across control groups. A comparison of intervention theories revealed that motivation enhancement (19\%) and contingency-based reinforcement (16\%) programs showed higher quit-rates than the overall intervention cessation mean. Regarding modalities (channels) of change, classroom-based programs showed the highest quit rates $(17 \%)$. Computer-based (expert system) programs also showed promise (13\% quit-rate), as did school-based clinics (12\%).

There was a fair amount of missing data and wide variation on how data points were measured in the programs' evaluations. Also, there were relatively few direct comparisons of program and control groups. Thus, it would be difficult to conduct a formal meta-analysis on the cessation programs. Still, these data suggest that use of adolescent tobacco use cessation interventions double quit rates on the average.

In the 17 self-initiated quitting survey studies, key predictors of quitting were living in a social milieu that is composed of fewer smokers, less pharmacological or psychological dependence on smoking, anti-tobacco beliefs (e.g., that society should step in to place controls on smoking) and feeling relatively hopeful about life. Key variables relevant to the quitting process may include structuring the context of programming for youth, motivating quit attempts and reducing ambivalence about quitting, and making programming enjoyable as possible. There also is a need to help youth to sustain a quit-attempt. In this regard, one could provide ongoing support during the acute withdrawal period and teach youth social/life skills. Since there is little information currently available on use of nicotine replacement in young people, continued research in this arena might also be a useful focus for future work.
\end{abstract}

KEY WORDS: adolescent tobacco use cessation 


\section{INTRODUCTION}

Most adolescents who use tobacco regularly (e.g., monthly or greater) continue use into adulthood. For example, while only five percent of adolescent smokers view themselves as smoking five years later, $75 \%$ actually are smoking eight years later [1]. Risk for developing tobacco-related disease increases as a function of duration of time tobacco is used [2, $3]$. Thus, adolescent users are at particularly high risk for physical consequences of tobacco use later on. These consequences begin their course in adolescence (e.g., HDL level changes; 4). Tobacco use prevalence among youth generally has been increasing over the last 15 years [3]. Until the last five years, little research has been completed to find ways to support young tobacco users to quit [5]. Possibly, people assumed that efforts aimed at getting teens to quit smoking simply don't work. However, the research and practice climates have changed. Ongoing efforts to provide teen cessation interventions have been initiated by numerous organizations. In the United States these organizations include the Centers for Disease Control, American Medical Association, National Institutes of Health (e.g., NCI, NIDA, NHLBI), American Lung Association, American Heart Association, and American Cancer Society [e.g., 6-8]. In Canada, these include Health Canada as well as various other Canadian governmental and private organizations. Numerous other countries are involved in similar efforts (e.g., Australia, India, Finland, Korea, Nigeria, and the UK; [e.g., 9-10]). Adolescent tobacco use cessation promises to arrest the physical consequences of use in a rapidly growing and developing body, and before the addiction becomes so ingrained that cessation becomes a much more difficult problem [11].

The present paper reviews adolescent tobacco cessation research completed to date. It builds on a previous review completed by Sussman, Lichtman, Ritt, \& Pallonen [12]. This paper examines numerous types of teen cessation efforts. These efforts include not only clinic programs, but also classroom-based efforts, computer expert system interventions, family programs, policy efforts (e.g., price increases, smoke-free areas, access reduction programs), mass media programming, and State-wide programs (there were two such programs, one was a mass media campaign and the other was multi-component). All of these efforts are referred to herein as "programs," in that they are organized programmatic efforts to produce a cessation or reduction effect. The term "intervention" is also used and is interchangeable with "programs." A total of 66 teen cessation programs are reviewed. Theories, modalities, methods, and results of these studies are provided. Examination of outcomes as a function of gender and ethnicity, theory-type, delivery modality, and number of sessions also is completed. A ranking of the evidence presented by the studies, based on outcomes and methodology, also is provided.

In addition, this paper provides a review of all known prospective self-initiated cessation survey studies. These are studies in which survey data on tobacco users is collected at two or more time-points. At baseline, tobacco users report various demographic, psychosocial, and behavioral sources of information. For example, they may report their gender and ethnicity, intention to quit tobacco use at a later time-point, and the number of cigarettes they smoke each day. These tobacco users are then surveyed at a later time-point. If these persons are found to have stopped smoking at the later time point, they are considered to have exhibited "self-initiated" cessation; that is, they have appeared to quit on their own without involvement in a formal quit- effort. By examining other variables measured at baseline, one can uncover predictors of later quitting (versus not quitting). A total of 17 such studies were found in the literature. Based on the results of these two types of studies - the formalized program and survey studies suggestions for future research and practice directions are made.

A total of 11 tables are included in the review. The first six tables provide all raw data points used to construct the program study summary. Identification of investigators, years the work was conducted, data on methodological design, program contents, the target population, recruitment, retention, and follow-up, and data on quitting and percentage reduction in tobacco use are described in these tables. The next three tables summarize these data as a function of program theory and modality, and rank programs on outcomes and methods. The last two tables show the methods and target populations for the self-initiated quit studies, and summarize the results of each of these studies.

\section{Sixty-Six Cessation Intervention Studies}

\section{Selection of Studies}

Among persons in the United States who have ever smoked daily, $16 \%$ have tried a cigarette, and $2 \%$ began smoking daily, by 12 years of age. Further, $82 \%$ have tried a cigarette, and $53 \%$ began smoking daily, by 18 years of age; and $98 \%$ have tried a cigarette, and $95 \%$ began smoking daily, by 25 years of age [2, p. 65]. Since most youth begin daily smoking by 25 years of age, the cessation studies included here generally targeted tobacco-using youth between the ages of 12 and 25 years old. However, seven studies were included that encompassed ages outside this range to allow the review to be as inclusive as possible. Three studies with wide age ranges included somewhat younger youth. Librett [13] included a through-study age range of 11-18; Patten et al. [14] included a through-study age range of 11-17; and Popham et al. [15] included a through-study age range of nine to 18 years. Also, four studies with wide age ranges included somewhat older adults. Etter, Ronchi, \& Perneger [16] included a through-study age range of 24-33; Glasgow et al. [17] included a through-study age range of 15-35; Quinlan \& McCaul [18] included a through-study age range of 18-55; and Zavela, Harrson, \& Owens [19] included a through-study age range of 18-39. 
The studies selected aimed to stop or reduce tobacco use among teens and young adults and included at least some data regarding contents of the cessation effort and attempts at quitting. Some of these programs targeted other age groups as well (e.g., older adults), but only data on teens and young adults were examined. Middle-school-based prevention programs were excluded from the present analysis because they did not supply any cessation information.

The contents of these programs could involve use of any cessation theory (e.g., social influence, motivation enhancement) and type of community unit to induce change (e.g., mass media, family, policy, or school). Thus, numerous theories and modalities of programming were included. All of these theories or modalities of program delivery were referred to as "programs", "Theory" refers to the theoretical content of the program. For example, an access reduction program, smoke-free areas, or taxes on cigarettes would be referred to as representatives of "supply reduction" theory, since they ultimately aim at making tobacco more difficult to obtain or use as a means to try to reduce tobacco use behavior. "Modality" refers to the community unit within which the cessation program is implemented. For example, use of a smoke-free area supply reduction approach (the theory) could be completed within one building, all public buildings in a city, or all public buildings throughout a state or country (different modalities).

The present 66 studies were compiled by referencing five different sources. Nineteen studies were included from a previous review on the subject [12]. Seventeen studies were presented as cessation programs in that earlier review. Two studies from that review were senior high school-based prevention programs, but they were included in the present review because these programs targeted a sizable number of baseline tobacco users and introduced some quit information. Seven more cessation studies were found in a review developed by Health Canada [20-21]. Twenty-six studies were found by engaging in a search of PsycINFO and MedINFO from 1970 to January, 2001. A subject search was performed using the phrases "adolescent tobacco", "tobacco cessation", "adolescent tobacco cessation" and "teen tobacco cessation". The references of all articles found were also searched but no additional articles were found. One study came from searching the World Wide Web, using the Google search engine [22]. Finally, 13 studies were found through word-of-mouth (from colleagues currently engaged in adolescent tobacco cessation work).

These five sources generated 66 tobacco-use cessation studies that probably are all the published or statistically evaluated cessation programs between 1975 and January 2001. Fifty studies were conducted in the United States, and 16 studies were conducted in countries outside of the U.S (five in Canada, three in the UK, two in Australia, and one each in China, Finland, New Zealand, Norway, Sweden, and Switzerland). Of these 66 studies, 47 had been or are going to be published in peer review journals. Six of these 66 studies were conducted in the 1970s, 15 were conducted in the 1980s, 43 were conducted in the 1990s, and two had been conducted in 2000-2001. Thus, teen tobacco use cessation research seems to have become a more active research arena beginning in the

Table 1. Cessation studies identification

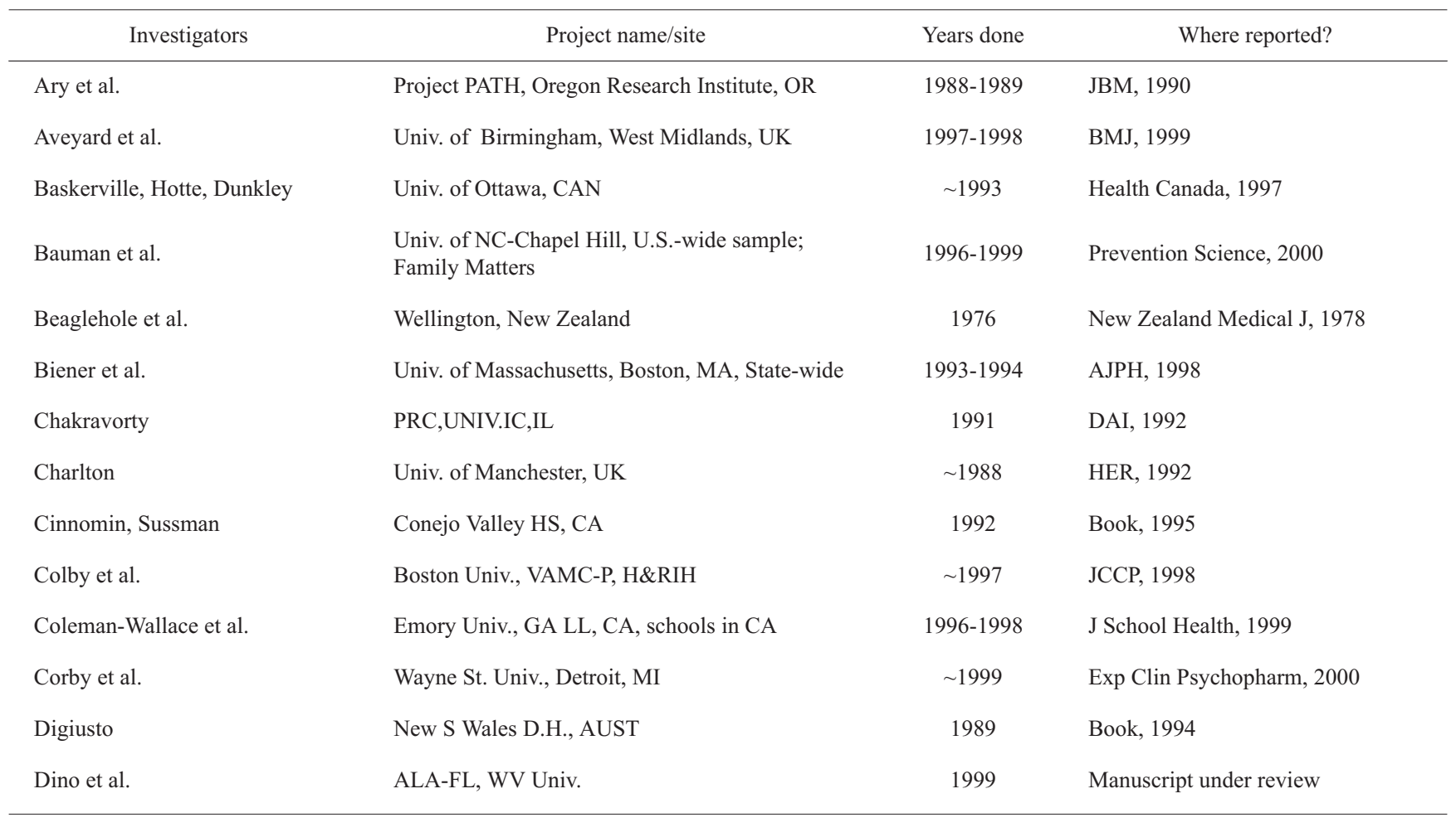


Table 1 (continued). Cessation studies identification

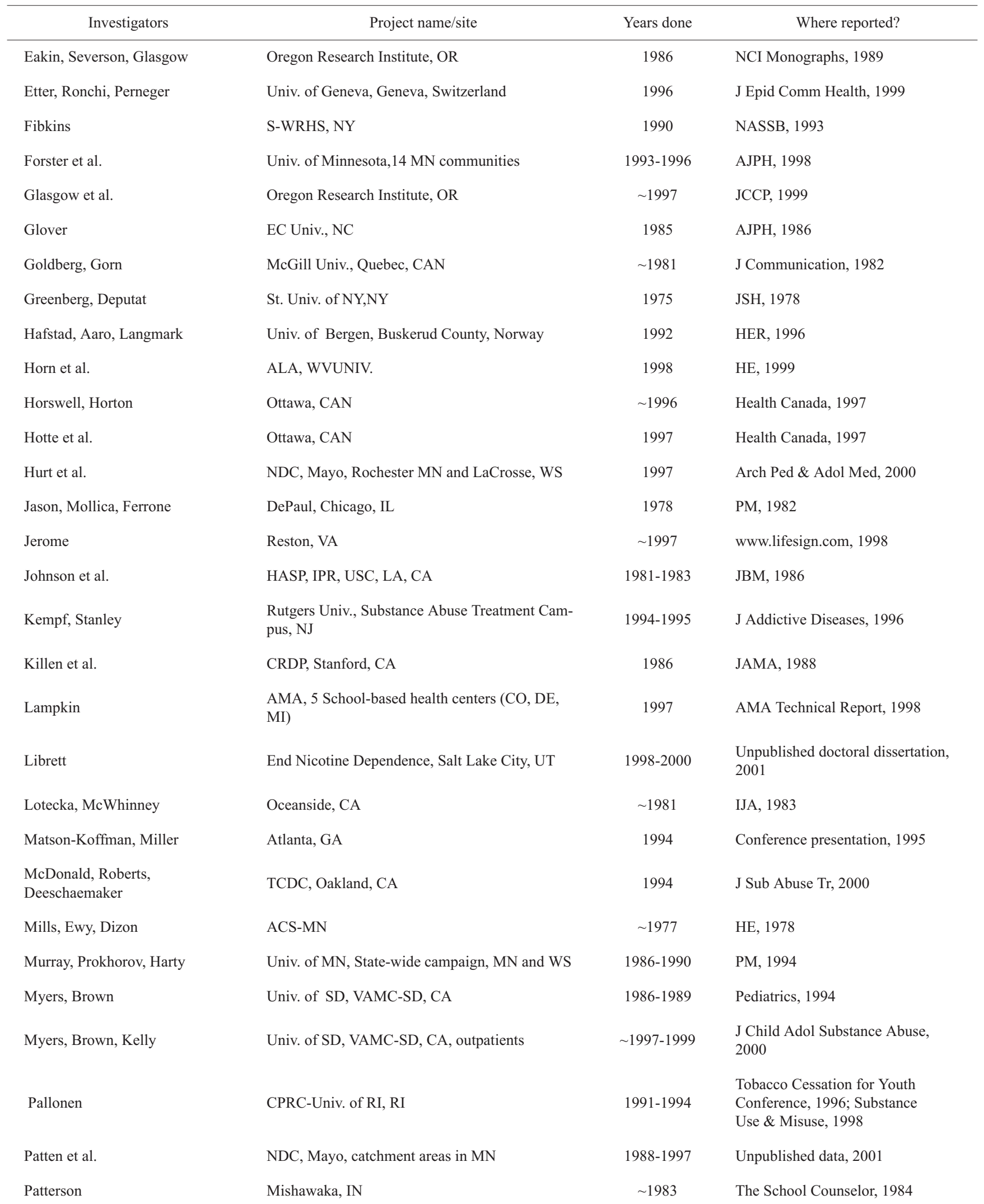


Table 1 (continued). Cessation studies identification

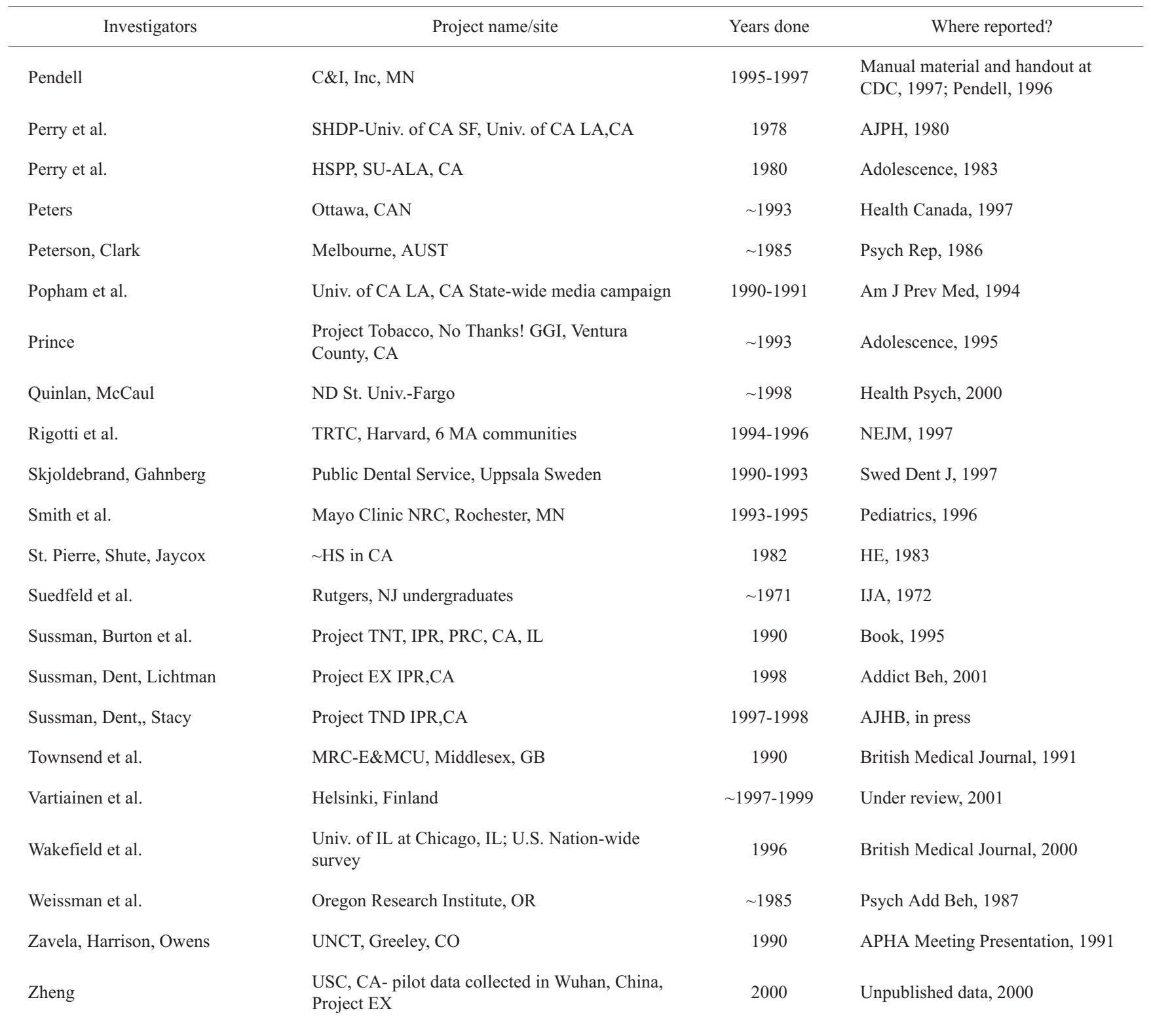

$\mathrm{NA}=$ not applicable; NR = not reported; for specifics on "Where reported?" see references section; = approximately.

1990s. Table 1 presents the 66 studies selected including investigators, project name, project site, year data was collected, and where the data was reported (see Table 1).

This review differs from most previous reviews that are typically completed in the arena of adolescent tobacco use prevention or cessation. Most previous reviews limited their selections to relatively rigorously evaluated studies consisting of at least a quasi-experimental design, which includes a program group comparison to a control group [2, 5, 23-25]. Use of a comparison group permits a calculation of relative quit-rates (program minus control). Single-group studies assess simply how many people quit in a particular treated group without comparison to a control [26]. These were included in the present review to increase the study sample size (considering the state of the science in this arena), and because in some cases use of a control group was not possible (e.g., in some of the policy-type studies).

A gross comparison measure was calculated by pooling control group estimates across the quasi-experimental and experimental studies. In addition, all studies that addressed teen cessation are included herein; from education-program efforts to policy or mass media efforts. Including single-group studies raised the total number of studies reviewed from 37 (15 experimental and 22 quasi-experimental) to 66 (see Table 2). 
Table 2. Cessation studies - methodological design

\begin{tabular}{|c|c|c|}
\hline Investigators & Methodological design & Bio-chemical validation? \\
\hline Aveyard et al. & $\begin{array}{l}\text { Experimental - two condition: expert system and three class sessions based } \\
\text { on transtheoretical model, standard health education (a little to motivate } \\
\text { quitting) }\end{array}$ & No \\
\hline Bauman et al. & Experimental - family program, standard care control & No \\
\hline Beaglehole et al. & Quasi-experimental - classroom program, standard care control & No \\
\hline Charlton & Quasi-experimental - pilot clinic (“courses"), self-help & Yes \\
\hline Cinnomin, Sussman & $\begin{array}{l}\text { Experimental - two condition: social influence/stress-coping, chemical } \\
\text { addiction }\end{array}$ & Yes \\
\hline Colby et al. & Experimental - two condition: motivational interview, brief advice & Yes \\
\hline Coleman-Wallace et al. & $\begin{array}{l}\text { Quasi-experimental - three condition: Tobacco Education Program (TEG) } \\
\text { for precontemplators, Tobacco Awareness Program (TAP) for those who } \\
\text { want to quit, control; } 57 \% \text { mandatory-punish (in TEG) }\end{array}$ & Yes \\
\hline Corby et al. & $\begin{array}{l}\text { Single-group - within subject replicated ABA design, } 1 \text { week each with a } \\
\text { two week follow-up }\end{array}$ & Yes \\
\hline & Quasi-experimental - two condition: & \\
\hline Etter, Ronchi, Perneger & $\begin{array}{l}\text { smoke-free program-four buildings/limited areas/cessation counseling ser- } \\
\text { vice, control (other buildings) }\end{array}$ & No \\
\hline Fibkins & Single-group - 1 group clinic & No \\
\hline Forster et al. & Experimental - two condition: policy program, standard care control & No \\
\hline Glasgow et al. & $\begin{array}{l}\text { Experimental - two condition: brief intervention, simple advice to quit } \\
\text { smoking }\end{array}$ & Yes \\
\hline Glover & Single-group - two pilot clinics & Yes \\
\hline Goldberg, Gorn & $\begin{array}{l}\text { Quasi-experimental - two condition: personal involvement, standard care } \\
\text { control }\end{array}$ & $\begin{array}{l}\text { No, did use behavioral } \\
\text { observation }\end{array}$ \\
\hline Greenberg, Deputat & $\begin{array}{l}\text { Quasi-experimental - four condition: fear, facts, values, standard care } \\
\text { control }\end{array}$ & No \\
\hline Hafstad, Aaro, Langmark & Single-group - mass media campaign for teens & No \\
\hline Horn et al. & $\begin{array}{l}\text { Quasi-experimental - two condition: not on tobacco (NOT), brief } \\
\text { intervention }\end{array}$ & Yes \\
\hline
\end{tabular}


Table 2 (continued). Cessation studies - methodological design

\begin{tabular}{|c|c|c|}
\hline Investigators & Methodological design & Bio-chemical validation? \\
\hline Hurt et al. & Single-group - nicotine patch therapy & Yes \\
\hline Jerome & Single-group - Life Sign computer assisted & Yes \\
\hline Johnson et al. & $\begin{array}{l}\text { Quasi-experimental - } 4 \text { condition: social curriculum/familiar media role } \\
\text { models, social curriculum/unfamiliar media role models, health curricu- } \\
\text { lum/familiar media role models, health curriculum/unfamiliar media role } \\
\text { models }\end{array}$ & Yes \\
\hline Lampkin & Single-group - pretest-posttest (averaged follow-up) & No \\
\hline Librett & Single-group - pretest-posttest & No \\
\hline Lotecka, McWhinney & Quasi-experimental - two condition: matched groups: coping, information & No \\
\hline Matson-Koffman, Miller & Single-group - quit and win/tobacco free teens, school clinic & NR \\
\hline McDonald, Roberts, Deeschaemaker & Single-group - consecutive cohorts & No \\
\hline Mills, Ewy, Dizon & Single-group - two cohorts, senior high and junior high & No \\
\hline Patten et al. & Single-group - retrospective cohort study & Yes, at baseline only \\
\hline Patterson & Single-group - feasibility study & No \\
\hline Pendell & Single-group - consecutive cohorts & No \\
\hline Perry et al. & $\begin{array}{l}\text { Quasi-experimental - two condition: special intervention, standard care } \\
\text { control }\end{array}$ & Yes \\
\hline Perry et al. & $\begin{array}{l}\text { Experimental - three condition: long-term health effects, social conse- } \\
\text { quences, physiological effects; also two teaching modalities (teacher, col- } \\
\text { lege student) }\end{array}$ & Yes \\
\hline Peters & Single-group - quit 4 life self-help kit requesters & No \\
\hline Peterson, Clark & $\begin{array}{l}\text { Quasi-experimental - two condition: discussion group, standard care con- } \\
\text { trol group }\end{array}$ & No \\
\hline Popham et al. & $\begin{array}{l}\text { Single-group - state-wide: looks at those exposed and not exposed to } \\
\text { campaign }\end{array}$ & No \\
\hline Prince & $\begin{array}{l}\text { Quasi-experimental - three condition: peer led, adult led, standard care con- } \\
\text { trol group }\end{array}$ & No \\
\hline
\end{tabular}


Table 2 (continued). Cessation studies - methodological design

\begin{tabular}{|c|c|c|}
\hline Investigators & Methodological design & Bio-chemical validation? \\
\hline Rigotti et al. & $\begin{array}{l}\text { Quasi-experimental - two condition: enforcement or non-enforcement of to- } \\
\text { bacco sales laws }\end{array}$ & No \\
\hline Skjoldebrand, Gahnberg & Single-group - all teens who came to the clinic for check-ups & No \\
\hline St. Pierre, Shute, Jaycox & $\begin{array}{l}\text { Single-group- group clinic pilot of ACS } \\
\text { I-Quit }\end{array}$ & No \\
\hline Suedfeld et al. & $\begin{array}{l}\text { Experimental - four condition: use of sensory deprivation (Senory D) cham- } \\
\text { ber or not, with a tobacco use health consequences message or not }\end{array}$ & No \\
\hline Sussman, Dent, Stacy & $\begin{array}{l}\text { Experimental - three condition: health educator led classroom, self-instruc- } \\
\text { tion, standard care control }\end{array}$ & Yes \\
\hline Townsend et al. & Single-group - "1-shot" & No \\
\hline Vartiainen et al. & Single-group- quit-and win approach & Yes \\
\hline Wakefield et al. & Nation-wide survey of the extent of smoking restrictions on teen smoking & No \\
\hline Weisman et al. & Single-group- AB design & Yes \\
\hline
\end{tabular}

$\mathrm{NR}=$ not reported

\section{Program Components}

Tobacco Product Focus. One study presented data on both cigarette smoking and smokeless tobacco use [27]. Four studies pertain only to smokeless tobacco use [19, 28-30]. The remaining studies address only cigarette smoking cessation.

Theoretical Contents. The theoretical contents of the 66-cessation studies selected were derived from several types of behavior change theoretical frameworks. It is a difficult task to try to delineate different theoretical structures since some programs use only small "pieces" of theories and others show both overlap and non-overlap of multiple theoretical contents. However, programs were grouped together that shared a similar general theoretical perception of teen cessation. Different groups of studies, while sharing some minimal overlapping features, reflect distinct approaches. The grouping produced seems reasonable; however, future work might consider grouping studies through use of multiple reviewers.
Collapsed across different modalities of programming, a total of eight types of theoretical foci seemed reflected in these studies:

1. Social influence-oriented: to combat social influences that serve to promote or maintain teen tobacco use.

2. Cognitive-behavioral: instruction in cognitive-behavioral self-monitoring and coping skills to quit and maintain tobacco use cessation (e.g., smoking diary, stress coping).

3. Motivation enhancement: techniques to clarify desire for change and reduce ambivalence toward change. This may include, but is not restricted to, a specific strategy such as motivational interviewing.

4. Response-contingent reinforcement: reinforce quit-behavior with the chance for extrinsic rewards such as money or prizes.

5. Supply reduction: arrange the social environment such that tobacco is more difficult to obtain or use (e.g., price increases or restricted access). 
6. Addiction/recovery-derived: use of means to ease physical effects of withdrawal, or emphasis on recovery from addiction.

7. Stages-of-change: techniques directly derived from the well-known model of change (e.g., tailored cost and benefit information, treating contemplation to quit and quit strategies as involving distinctly different processes of change).

8. Affect clarification: techniques to clarify and remove conflicted affect, and thereby permit pursuit of health including tobacco use cessation.

Eleven studies attempted to counteract social influences to use tobacco [15, 31-40]. In these studies, the key information provided to help youth quit smoking was focused on combating social influences that may maintain smoking behavior. Such information included refusal assertion skill instruction, instruction in awareness of tobacco industry promotions, media and peer social influences, and correction of social informational inaccuracies. While sharing this common focus on counteraction of social influences that may maintain tobacco use, some of these programs also contained notable unique features. The Beaglehole et al. study [32], for example, addressed physical consequence information as well as social influence information using the health belief model as a teaching guide. Killen and colleagues [36] focused on the social attractiveness of exercise and healthy food intake, as well as on smoking behavior. Peterson \& Clark [39] focused on instruction in social influences and smoking, and also placed a focus on group decision-making to cut down on smoking levels. Finally, Townsend and colleagues [40] focused on normative social influence (i.e., conformity to achieve acceptance) by teaching skills such as refusal assertion, rather than by attempting to counteract more covert social informational influences that aim to achieve attitudinal similarity (e.g., counteracting media influence). Conducted in a medical office, this study also addressed physical consequences information and general health practices [40].

Sixteen studies $[8,13-14,23,27,29,30,41-50]$ focused on instruction of cognitive-behavioral coping techniques. In particular, they focused on uncovering the topography of one's tobacco use (e.g., reasons for smoking and quitting, self-monitoring) and how to cope effectively with stress (e.g., seek out social support, relaxation, wait out urges, self-management, problem solving). While most of these programs discussed at least briefly counteraction of social influences and chemical dependence (e.g., coping with withdrawal symptoms), the emphasis was on intra-personal coping. One unique aspect here is that two studies grouped coping with different functions of tobacco use in separate conditions [27, 42]. For example, Sussman et al. [27] compared coping with psychosocial dependency on tobacco separately from coping with chemical addiction to tobacco. Eakin and colleagues [29] introduced a pneumonic device, the "Four A's": Avoid, Alter, Alternatives, and Activities, as a strategy for coping with the difficulty of cessation.
Nine studies emphasized motivation enhancement [17, 51-59]. These studies dedicate a significant percentage of the program to making an attempt to increase smokers' motivation to quit smoking prior to providing instruction in life skills, social influences, and/or chemical dependence. Motivation enhancement helps participants to clarify their direction of change and increases their willingness to change. Motivation enhancement may include such strategies as giving advice, removing cognitive impediments to change, providing choices, and reconciling discrepancies between current behavior and desired goals [60-61]. Within this set of studies, two emphasized a single type of motivation manipulation - the notion of establishing cognitive consistency. Specifically, Goldberg \& Gorn [54] made use of the concept of personal involvement to try to get college-age smokers to quit by serving as mentors of younger youth, as part of a tobacco education/communications class. Hafstad, Aaro \& Langmark [55] contrasted popular opinions and realities of being a smoker as part of a mass media program.

Five studies emphasized principles of response-contingent reinforcement [62- 66]. The main goal was to test whether an offer of an extrinsic reinforcement or the possibility of reinforcement to participants would decrease the frequency of tobacco use behavior $[61,67]$. Among this set of studies, three made use of a Quit-and-Win Contest concept combined with a primarily a chemical addiction orientation $[62,64-65]$. Two studies were contingency-based $[63,66]$. Corby and colleagues [63] developed a very brief contingency-based study to learn about the effects of contingencies on initial cessation; Weissman et al. [66] designed a contingency focused study with a 15-20-session clinic program that rewarded adequate participation with money.

Seven studies took primarily a supply reduction approach. Supply reduction approaches aim to arrange the environment in such a way that tobacco is more difficult to obtain or use [68]. By making tobacco harder to obtain or use, it is theorized that costs (financial, time, or social) of tobacco use increase for users and that they may have more reason to think about quitting. In addition, supply reduction approaches provide a large social environmental statement of disapproval regarding tobacco use. There are at least three types of supply reduction approaches. One approach is taxation to raise the price of tobacco $[69,71]$. One may expect that a percentage increase in the price of tobacco will result in a corresponding increase in quit-rates. A second supply reduction approach is the establishment of smoke-free areas to limit where tobacco can be smoked $[16,70]$. A third approach consists of limitations on where and by whom tobacco can be purchased or obtained [72-74], reducing overall access to tobacco products. One unique study, Wakefield et al., [74] examined the effects of access reduction across multiple contexts. Another one of these studies also included social influence education, in addition to use of multiple supply reduction approaches [71].

Nine studies took a primarily addiction/recovery approach $[19,22,28,75-80]$. These programs emphasized strategies to 
ease the physical effects of withdrawal/addiction (use of pharmacological adjuncts or substitutes) or emphasized recovery from physical addiction.

Smith et al. [80] and Hurt et al. [76] studied the provision of nicotine patches to teens, and Hurt made use of a physician-assisted model developed for adults (the 4-A's, ask, advice, assist, arrange follow-up). Jerome's [22] study involved the use of a hand-held computer to facilitate gradual withdrawal from nicotine (LifeSign) combined with attendance at weekly support groups. Three studies focused on providing support groups modeled on twelve-step programs [75, 77-78]. Two studies, Chakravorty [28] and Zavela, Harrison, and Owens [19], were substitution-based studies. Both studies were developed for smokeless tobacco users, and they substituted tobacco use with use of a non-tobacco, crushed mint leaves product (Mint Snuff, Oregon Mint Snuff Co., 1-800-EAT-MINT). A final study involved screening in a dental clinic, provision of dental professional advice, and referral to a nicotine detoxification program [79].

Seven studies [7, 18, 81-85] were Transtheoretical (stages of change) model-based. In this model program material is framed for the participants stage of change, to help facilitate the subjects' movement through the quitting process [also see 86-87]. These stages are: 1 ) precontemplation, during which a smoker has not considered quitting; 2) contemplation, during which a smoker is thinking about quitting; 3 ) preparation, during which a smoker is prepared to quit; 4) action, during which a smoker is actively involved in quitting; and 5) maintenance, during which a smoker has quit and is trying to stay off tobacco. Program contents were tailored to the appropriate stages of change of participants. Early in the stages of change, subjects' costs minus benefits of smoking are calculated (e.g., financial, social costs versus withdrawal reduction benefits), and self-reevaluation and insight are obtained (the subject decides to quit when perceived costs are reliably greater than benefits). Later in the stages of change, various skill-building and quitting behaviors are learned. Pendell's work $[82,85]$ includes two different programs, the Tobacco Education Group (TEG) and the Tobacco Awareness Program (TAP). The TEG program addresses specifically adolescents at the precontemplative or contemplative stage, while the TAP program addresses specifically those students at the preparation, action, and maintenance stages. Quinlan and McCaul [18] made use of stage of change concepts within a brief university-based quit-clinic. Mills and colleagues [83] made use of social influence and buddy-contracting concepts, as part of later stages of change action steps. Lampkin's [7] study made use of a brief motivation enhancement interview, although it focused on stages of change concepts. Aveyard et al. [81] and Pallonen's [84, 86,88] programs were computer-based and provided relatively specific tailored feedback depending on the participant's stage of change.

Finally, two studies involved an affective education-type approach. These are based on the premise that through clarification or release of conflicted - or pent-up - affect, the participant returns to a healthy affective state which would subsequently lead to elimination of unhealthy behavior such as smoking. Greenburg and Deputat's [89] study focused on an affective education/values clarification model, comparing it to information and fear approaches. Suedfeld et al. [90] involved use of a sensory deprivation chamber to "unfreeze" attitudes and permit smoking cessation.

Modality of Programming. Modality refers to the channels or contexts within which the cessation programming is offered. Seven modalities of programming were delineated. These were school-based clinics, medical or recovery clinics, system-wide efforts, classroom-based, computer-based, family-based, and use of a sensory deprivation chamber.

In twenty-eight studies programming was delivered in a school-based clinic, the most popular modality (43\%). School-based clinics involve the implementation of highly interactive, private sessions for small groups of youth developed specifically for tobacco use cessation, on the grounds of schools. These clinics are composed of students from the school, but are delivered outside of the regular classroom context. Generally, five to 15 youths will participate in each clinic group in an empty classroom or office, and groups often will meet during school hours. Frequently, youth are released from class to attend the clinic.

Another 13 studies involved a medical or recovery clinic. These efforts often are similar to school-based clinics but involve attendance at a medical or recovery facility. In some cases, youth are treated individually in addition to or in place of within a group context.

Another 11 studies involved system-wide efforts (e.g., mass media campaigns, policy, or statewide). These efforts involve delivery of programming to complete or multiple social units (i.e., applies to everyone in a building, set of buildings, community, or even larger units such as states). As such, programming is delivered to very large numbers of people, and may involve different combinations of modalities (e.g., schools, the mass media, local business, and city leaders). Such programming may include various demand reduction and/or supply reduction components [68]. Thus, while the theory in operation may vary across different system-wide studies, the resulting program contents are delivered widely.

A total of 9 studies were classroom-based. This programming was delivered within intact classrooms as part of a classroom course. Three additional studies employed the use of computers (i.e., "expert systems" - iterative feedback from experts within a computer modality, hand-held or PC), primarily as a means of delivering a self-help program. While sometimes placed in a school setting computer lab, youth could use the computer tailored to their level of tobacco use and interest in quitting. In this case, the programming is tailored to the individual, who can set up his/her own time to use the material. One study was a family-based intervention [51], which involved self-help and telephone counseling to parents and their 12-to-14 year old children (focused on the home setting). 
Table 3. Cessation studies - program contents

\begin{tabular}{|c|c|c|c|}
\hline Investigators & Theoretical guide & Modalities & \#Sessions \\
\hline Aveyard et al. & $\begin{array}{l}\text { Stages of change model - norma- } \\
\text { tive/ipsative feedback, smoking } \\
\text { pros/cons; control-information on health }\end{array}$ & $\begin{array}{l}\text { Three computer expert system lessons and three } \\
\text { classes }\end{array}$ & 6 \\
\hline $\begin{array}{l}\text { Baskerville, } \\
\text { Hotte, Dunkley }\end{array}$ & $\begin{array}{l}\text { Contingency-based, quit-and-win con- } \\
\text { test contingent on smoke free month, } \\
\text { buddy support, chemical addiction }\end{array}$ & $\begin{array}{l}\text { System-wide, school-based contest and self-help } \\
\text { materials, youth signed up from } 10 \text { high schools }\end{array}$ & NA \\
\hline Bauman et al. & $\begin{array}{l}\text { Motivation enhancement, parenting, } \\
\text { modeling, social influences }\end{array}$ & Family-directed, through mail and phone calls & $\begin{array}{l}\text { NA } \\
\text { ( } 5 \text { booklets, } \\
15 \text { activities })\end{array}$ \\
\hline Beaglehole et al. & $\begin{array}{l}\text { Social influence and health belief model } \\
\text { versus standard care fear information } \\
\text { and discussion }\end{array}$ & Classroom program with films & $\begin{array}{l}\quad \mathrm{NR} \\
\text { (semester } \\
\text { course) }\end{array}$ \\
\hline Chakravorty & $\begin{array}{l}\text { Substitution (chemical addiction) and } \\
\text { education }\end{array}$ & School clinic & 2 \\
\hline Charlton & Cognitive-behavioral - "Packing it in?" & School clinic or self-help & 6 \\
\hline Cinnomin, Sussman & $\begin{array}{l}\text { Cognitive-behavioral, social influences, } \\
\text { chemical addiction }\end{array}$ & School clinic & 6 \\
\hline Colby et al. & Brief motivation enhancement-oriented & Medical hospital clinic & 1 \\
\hline Coleman-Wallace et al. & $\begin{array}{l}\text { Stages of change - TEG and TAP; } \\
\text { cognitive-behavioral }\end{array}$ & Mostly school clinic, videos, cooperative learning & 8 \\
\hline $\begin{array}{l}\text { Eakin, } \\
\text { Severson, Glasgow }\end{array}$ & $\begin{array}{l}\text { Cognitive-behavioral, coping skills - } \\
4 \text { As }\end{array}$ & $\begin{array}{l}\text { At Oregon Research Institute, school-like clinic, } \\
\text { small group meetings, 2-3 counselors, videos }\end{array}$ & 3 \\
\hline Etter, Ronchi, Perneger & $\begin{array}{l}\text { Supply reduction, policy, information } \\
\text { campaign, self-help }\end{array}$ & $\begin{array}{l}\text { System-wide, smoke-free areas, posters, leaflets, } \\
\text { self-help quit manuals at part of university }\end{array}$ & NA \\
\hline Fibkins & $\begin{array}{l}\text { Recovery/addiction, student assistance } \\
\text { counseling model, recovery concepts: } \\
\text { "Five Hour a Day" }\end{array}$ & School clinic with counselor and nurse & 6 \\
\hline Forster et al. & $\begin{array}{l}\text { Supply reduction; make youth tobacco } \\
\text { access a salient issue, change } \\
\text { ordinances, change retailer and parent } \\
\text { practices, enforcement of sale laws }\end{array}$ & $\begin{array}{l}\text { System-wide, community organizer teams, group } \\
\text { presentations, letter and petition drives, meetings } \\
\text { with community leaders and retailers, media cam- } \\
\text { paigns, purchase attempts }\end{array}$ & NA \\
\hline Glasgow et al. & $\begin{array}{l}\text { Brief motivation enhanced-oriented and } \\
\text { follow-up support phone calls }\end{array}$ & $\begin{array}{l}\text { Medical-like planned parenthood clinic, short } \\
\text { video, brief counseling, } 1-3 \text { phone calls }\end{array}$ & $1-2$ \\
\hline Glover & Cognitive-behavioral-ACS Fresh Start & College/school clinic & 2 \\
\hline Goldberg, Gorn & $\begin{array}{l}\text { Motivation enhancement, personal in- } \\
\text { volvement to help younger youth }\end{array}$ & $\begin{array}{l}\text { College classroom program, films, advertisement } \\
\text { analysis, social influence texts, discussion }\end{array}$ & $\sim 16$ \\
\hline Greenberg, Deputat & Affect-oriented, fears, facts or values & School clinic, films & 7 \\
\hline
\end{tabular}


Table 3 (continued). Cessation studies - program contents

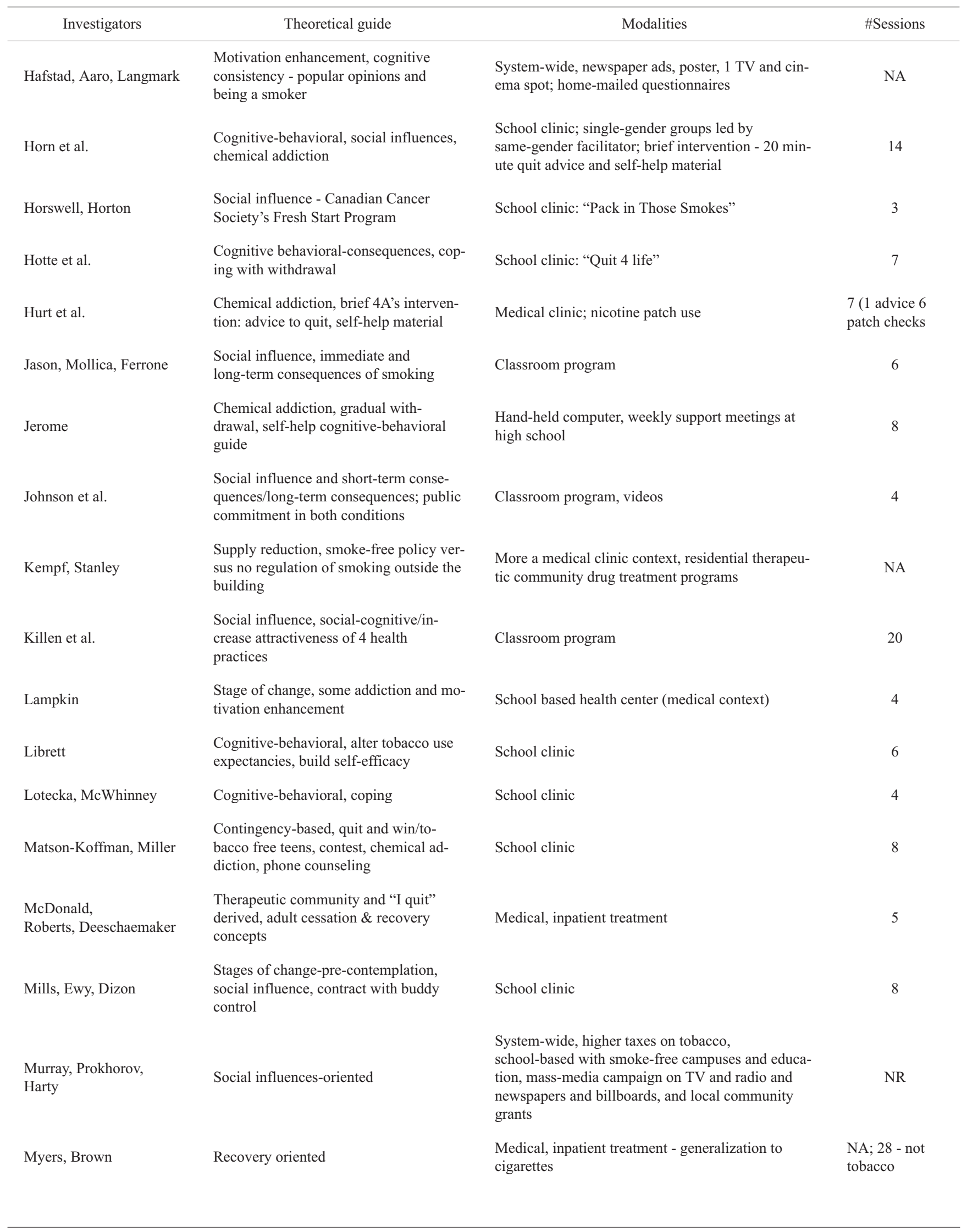


Table 3 (continued). Cessation studies - program contents

\begin{tabular}{|c|c|c|c|}
\hline Investigators & Theoretical guide & Modalities & \#Sessions \\
\hline Pallonen & Stages of change & Computer assisted & 3 \\
\hline Patten & $\begin{array}{l}\text { Cognitive-behavioral, chemical addic- } \\
\text { tion, social influence }\end{array}$ & $\begin{array}{l}\text { Medical clinic consultation, telephone and mail } \\
\text { follow-up }\end{array}$ & 2 \\
\hline Pendell & Stages of change -TEG and TAP & Mostly school clinic, videos, cooperative learning & 16 \\
\hline Perry et al. & Comprehensive social influences & $\begin{array}{l}\text { Prevention and cessation in classroom program, } \\
\text { films, self-monitoring }\end{array}$ & 4 \\
\hline Peterson, Clark & $\begin{array}{l}\text { Social influence, group decision to cut } \\
\text { down }\end{array}$ & School clinic & 3 \\
\hline Popham et al. & $\begin{array}{l}\text { Social influence, health and social conse- } \\
\text { quences, society's disapproval, profit } \\
\text { motivation of tobacco industry }\end{array}$ & $\begin{array}{l}\text { System-wide, TV, radio, outdoor and print media. } \\
13 \text { general audience ads, } 2 \text { youth-focused ads }\end{array}$ & NA \\
\hline Prince & Cognitive behavioral & School clinic & 6 \\
\hline Quinlan and McCaul & $\begin{array}{l}\text { Stages of change-pre-contemplation } \\
\text { (costs and benefits), action (quit tech- } \\
\text { niques and quit date) }\end{array}$ & $\begin{array}{l}\text { Brief university clinic-two activities and take home } \\
\text { materials }\end{array}$ & 1 \\
\hline Smith et al. & Addiction model & $\begin{array}{l}\text { Medical clinic-like, patch, behavioral counseling } \\
\text { with group support-coping, wellness, relapse } \\
\text { prevention }\end{array}$ & 8 \\
\hline St.Pierre, Shute, Jaycox & $\begin{array}{l}\text { Cognitive-behavioral, I-quit, } \\
\text { psychosocial dependency, chemical } \\
\text { addiction }\end{array}$ & School clinic, video & 6 \\
\hline Suedfeld et al. & $\begin{array}{l}\text { Affect-oriented, SD to "unfreeze" atti- } \\
\text { tudes and permit change }\end{array}$ & $\begin{array}{l}\text { University lab; sensory deprivation (Sensory D) } \\
\text { chamber }\end{array}$ & $\begin{array}{l}124 \text { hour Sen- } \\
\text { sory D session }\end{array}$ \\
\hline Sussman, Burton et al. & $\begin{array}{l}\text { Cognitive-behavioral, psychosocial de- } \\
\text { pendency and chemical addiction }\end{array}$ & School clinic, videos & 5 \\
\hline $\begin{array}{l}\text { Sussman, } \\
\text { Dent, Lichtman }\end{array}$ & $\begin{array}{l}\text { Motivation enhancement, with social in- } \\
\text { fluences and chemical addiction } \\
\text { material }\end{array}$ & $\begin{array}{l}\text { School clinic, school meetings and events in } 1 \\
\text { condition }\end{array}$ & 8 \\
\hline Sussman, Dent, Stacy & $\begin{array}{l}\text { Motivation enhancement-skills-decision } \\
\text { making-chemical addiction }\end{array}$ & Continuation high school classroom program & 12 \\
\hline
\end{tabular}


Table 3 (continued). Cessation studies - program contents

\begin{tabular}{|c|c|c|c|}
\hline Investigators & Theoretical guide & Modalities & \#Sessions \\
\hline Vartiainen et al. & $\begin{array}{l}\text { Contingency-based, quit-and-Win } \\
\text { lottery (for } \sim \$ 1,600 \text { ) }\end{array}$ & $\begin{array}{l}\text { System-wide, through schools, biochemically vali- } \\
\text { dated quitting to enter lottery }\end{array}$ & NA \\
\hline Wakefield et al. & $\begin{array}{l}\text { Supply reduction: restrictions on smok- } \\
\text { ing at home, school and public places }\end{array}$ & System-wide, cross-sectional survey; self-reports & NA \\
\hline Zavela, Harrison, Owens & $\begin{array}{l}\text { Substitution (addiction), with coping- } \\
\text { oriented material }\end{array}$ & College clinic & 9 \\
\hline Zavela, Harrison, Owens & $\begin{array}{l}\text { Substitution (addiction), with coping- } \\
\text { oriented material }\end{array}$ & College clinic & 9 \\
\hline
\end{tabular}

$\mathrm{NA}=$ not applicable; $\mathrm{NR}=$ not reported

Finally, one study [90] involved use of a sensory deprivation chamber at a university lab (see Table 3 ).

It should be mentioned that the division of programming by theory and modality is sound logically, however two theories tended to be associated with certain modalities of delivery. Social influence programming tended to be delivered in a classroom setting (in seven of 11 instances of its use) and cognitive-behavioral programming tended to be delivered in a school-based clinic setting (in 14 of 16 instances of its use). The other theories and modalities were more evenly crossed in design. Thus, interpretation of main effects findings on theory and modality needs to be tempered by this information.

Number of Sessions. Number of sessions was defined herein simply as the total number of meetings without respect to the length of the meetings or spacing of the meetings. Number of sessions is not an appropriate measure for 15 studies, which involved non-educational type programming such as supply reduction policy enforcement. However, amount of exposure to non-educational programming is an important factor and generally was of a year or more duration. Also, two educational-type programs failed to indicate number of sessions (see Table 3). Of the 49 programs that report number of sessions, the mean number of sessions was 6.7 (the mode was six sessions, 11 programs; then eight sessions, seven programs; then three sessions, five programs; then one or two sessions, four programs each), and the range was from one to 20 sessions. This is an important variable to measure because, for the educational-type of program, it is possible that number of sessions is related to program success. Specifically, the greater the number of sessions the more potent the effect may be. This type of relation is found among teens in drug abuse prevention programming [91] and among adults in tobacco use cessation programming [92]. The relation of number of sessions to program outcomes will be examined in the program outcomes section below.

\section{Methodological Design}

The most widely used methodological design was single-group. Twenty-nine single group studies evaluated cessation rates in a program group without comparison to a control; 22 quasi-experimental studies utilized a control group to compare naturally occurring cessation rates with those occurring in the program condition; and 15 studies utilized random assignment to conditions in order to maximize experimental validity. Reliance on single-group design was explained in one study by the difficulty encountered in recruiting enough tobacco users to create a control group [29]. Another study reported that the main purpose of the study was to test level of adolescent interest and willingness to continue participation regardless of actual cessation rates [88]. Thus, a control group of smokers may have been unwarranted considering the focus. Other studies used a single group design as a means of pilot testing a program for later work [e.g., 7]. Still, other work examined community-wide efforts [e.g., 69]. Finding an appropriate control group for community-wide efforts is very difficult and sometimes is not possible. In the case of such system-wide efforts, comparisons generally are made to nation-wide trends, based on deterioration of effects after termination of programming, or through replications in different locations. The Canadian Tobacco Control Research Initiative (CTCRI), when considering "best practice" programs, takes a widely shared stance that replications across quasi-experimental and case study designs are considered appropriate designs for evaluating community-based interventions [93]. The predominance of use of a single group design indicates a need for more rigorous research designs in adolescent tobacco cessation (see Table 2). However, wise use of quasi-experimental designs and replications of single group designs can permit 
Table 4. Cessation studies - target population

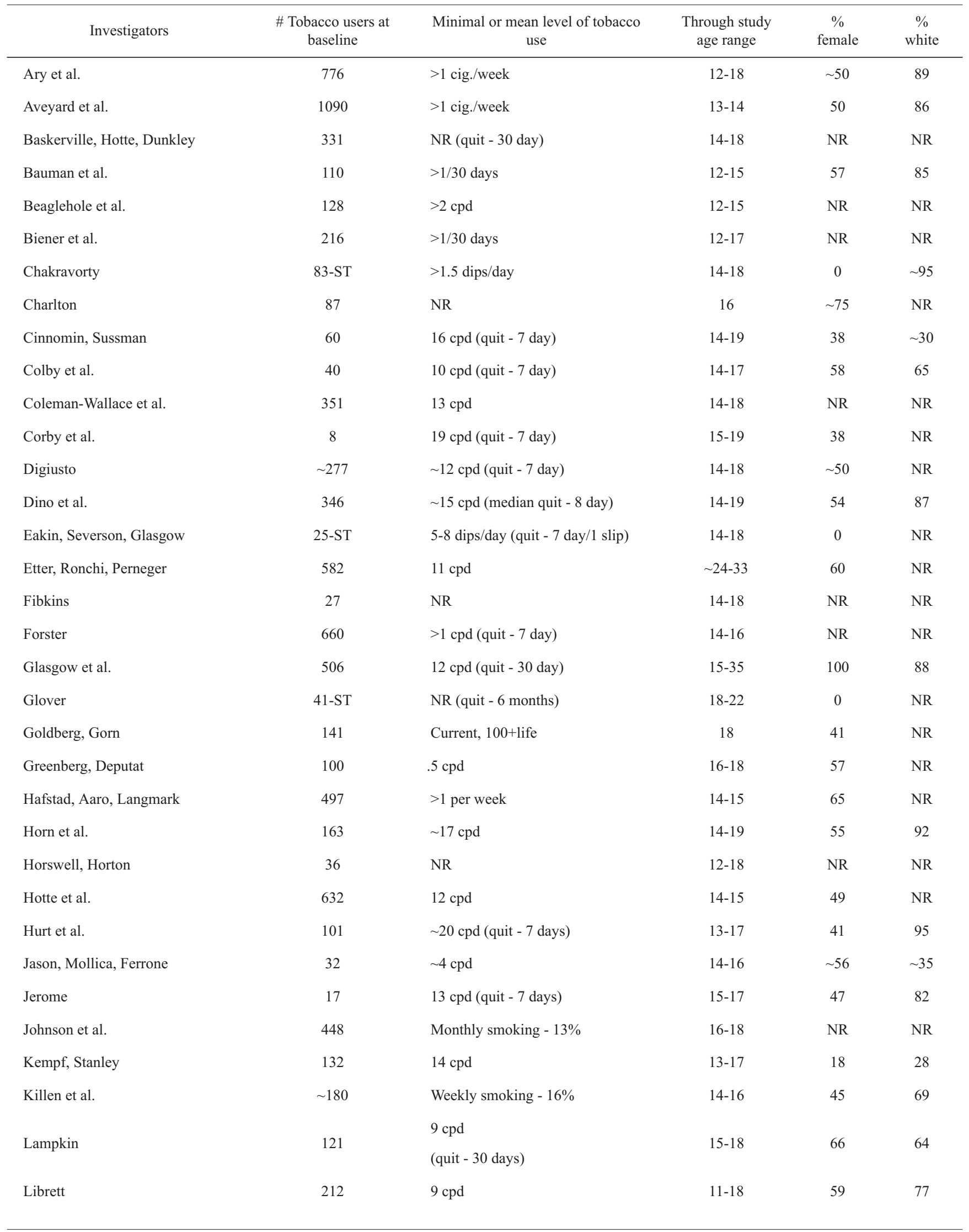


Table 4 (continued). Cessation studies - target population

\begin{tabular}{|c|c|c|c|c|c|}
\hline Investigators & $\begin{array}{l}\text { \# Tobacco users at } \\
\text { baseline }\end{array}$ & $\begin{array}{c}\text { Minimal or mean level of tobacco } \\
\text { use }\end{array}$ & $\begin{array}{l}\text { Through study } \\
\text { age range }\end{array}$ & $\begin{array}{c}\% \\
\text { female }\end{array}$ & $\begin{array}{c}\% \\
\text { white }\end{array}$ \\
\hline Lotecka, McWhinney & 49 & 7 cpd (quit - 7 days) & $14-18$ & NR & NR \\
\hline $\begin{array}{l}\text { McDonald, Roberts, } \\
\text { Deeschaemaker }\end{array}$ & 51 & $\begin{array}{l}27 \text { cpd } \\
\text { (quit - } 7 \text { days) }\end{array}$ & $12-19$ & 46 & NR \\
\hline Murray, Prokhorov, Harty & 450 & $>1$ per week & $14-15$ & NR & NR \\
\hline Myers, Brown & 141 (last 3 months) & $13 \mathrm{cpd}$ (quit - 7 days) & $12-18$ & 40 & 79 \\
\hline Myers, Brown, Kelly & 35 & $>1$ per week & $13-18$ & 40 & 71 \\
\hline Patterson & 21 & NR (quit - 2 days) & $14-18$ & NR & NR \\
\hline Pendell & 3955 & NR & $12-18$ & NR & NR \\
\hline Perry et al. & 243 & $>1$ per month $-27 \%$ & 16 & 54 & NR \\
\hline Perry et al. & 82 & $>1$ per week & 16 & $\sim 50$ & NR \\
\hline Peters & 635 & $>1$ cpd (quit - 7 days) & $15-19$ & NR & NR \\
\hline Peterson, Clark & 22 & $8 \mathrm{cpd}$ & $14-16$ & 100 & NR \\
\hline Popham et al. & 7000 & $>1$ per month $-13 \%$ & $9-18$ & 53 & 50 \\
\hline Smith et al. & 22 & $23 \mathrm{cpd}$ (quit - 7 days) & $13-17$ & 68 & NR \\
\hline St. Pierre, Shute, Jaycox & 12 & NR & $16-18$ & 42 & NR \\
\hline Suedfeld et al. & 40 & $18 \mathrm{cpd}$ & $19-22$ & 0 & NR \\
\hline Sussman, Burton et al. & 244 & NR (quit - 7 days) & $14-18$ & 50 & 60 \\
\hline Sussman, Dent, Lichtman & 335 & $8 \mathrm{cpd}$ (quit - 30 days) & $14-19$ & 36 & 27 \\
\hline Sussman, Dent, Stacy & 583 & $\sim 8$ cpd (quit - 30 days) & $14-19$ & 34 & 43 \\
\hline Townsend et al. & 68 & 7 or more cpd & $13-17$ & 54 & NR \\
\hline Vartiainen et al. & 3241 & $>1$ per month $(\sim 8$ per month $)$ & $15-24$ & 45 & NR \\
\hline Wakefield et al. & 14,746 & $>1$ per month & $14-17$ & 54 & 47 \\
\hline Weissman et al. & 11 & 18.5 cpd (quit - 7 days) & $13-18$ & 46 & NR \\
\hline Zavela, Harrison, Owens & $42-\mathrm{ST}$ & 7.6 dips per day & $\begin{array}{c}18-39 \\
(\text { mean }=20.7)\end{array}$ & 3 & NR \\
\hline Zheng & 46 & 5 cpd (quit - 7 day) & $16-17$ & 7 & 0 \\
\hline
\end{tabular}


inferences regarding relatively strong or weak programming [26].

Biochemical Validation. Three biochemical methods that have been used for over 10 years with adults and teens include exhaled carbon monoxide (CO), saliva thiocyanate $(\mathrm{SCN})$, and saliva cotinine measurement [27]. Most teen cessation studies have used CO measurement perhaps because cost of analysis is the least expensive, even though it has a relatively brief half-life of three to five hours. Biochemical validation was reported in 30 studies (see Table 2). There is recent debate concerning applicability of biochemical validation to adolescent regular tobacco users considering that teens may metabolize nicotine differently (e.g., more quickly) than adults (suggested by Henningfield at CDC, 1997, personal communication). Further, some researchers suggest that use of this procedure may discourage participation in cessation programming [e.g., 46], or may not be imperative if multiple self-report measures are used [e.g., 94]. Still, approximately $15 \%$ of adolescents who report cessation are detected as still using tobacco when concurrent biochemical validation measures are collected [e.g., 27, collected saliva cotinine; 57, collected carbon monoxide (CO) breath samples]. Since biochemical validation may produce more accurate rates of cessation, this means of validation should be considered when reporting adolescent tobacco use cessation data.

\section{Target Population}

Number of Baseline Tobacco Users. Across all 66 studies, a mean of 659.5 adolescent or young adult tobacco users participated at baseline in the cessation studies (range $=$ eight to 14,746$)$. Tobacco use was defined for this statistic as the total number of users of any type of tobacco product, regardless how tobacco "use" was defined by the individual studies. The number of tobacco-using subjects at baseline was 90 or fewer subjects in 26 studies, was between 91 and 150 subjects in 13 studies, was between 151 and 400 subjects in 11 studies and was 401 or greater in 16 studies. Half the studies $(n=33)$ contained 120 or fewer subjects, two-thirds of the studies contained fewer than 211 subjects, and $75 \%$ of the studies contained fewer than 400 subjects (see Table 4). Of the 25 studies that contained more than 200 subjects, four were a classroom-based modality, one was expert system based, 11 were system-wide programs, eight were school-based clinics, and one was a medical-oriented clinic. Thus, all modalities except for family based and sensory deprivation (one study in each category) contained at least one study with a large sample size.

The fact that half of the studies included 120 or fewer participants, many involving two or more conditions in the design, highlights that much of the work completed in teen cessation research is completed with under-powered samples. (For example, to achieve an effect size $=0.2$ with $80 \%$ power, in a simple two-group design, a sample size of approximately 190 would be needed in each group, 1-tailed, $\mathrm{p}<.05$; or 380 subjects would be needed if the study was two-tailed).
Age. As mentioned previously, the target age for these adolescent cessation studies was between 12 and 25 years old. However, seven studies were included in which target ages were outside this range. These exceptions were made because most of the youth in these seven studies fell within the targeted 12-24 years old age range, and the review was designed to be as inclusive as possible. Thus, age in the study set ranged from nine to 55 years old. Collapsing age range across studies, the modal ages are as follows: 16 years old (54 studies), 15 (51 studies), 14 (46 studies), 17 (46 studies), 18 (40 studies), 13 (19 studies), 12 (13 studies) and 19 years old (13 studies). A total of three or fewer studies looked at people 11 years old or younger. Among the studies that included nine to 11 year olds (as well as older youth), one was a school-based clinic [13], one was a medical-based clinic [14], and one was a system-wide study (statewide campaign; [15]). A total of seven studies looked at people 20 years or older. The Etter, Ronchi, \& Perneger [16], Glasgow et al. [17], Glover [30], Quinlan \& McCaul [18], Suedfeld et al. [90], Vartiainen et al. [65], and Zavela, Harrison, \& Owens [19] studies, which examined older youth and adults, primarily were college-based studies. Within-study ranges reflect the "through-study" age range or the youngest age of those who were participating at the beginning of the study and the oldest age of those who were participating at the end of the study (see Table 4).

Gender and Ethnicity. Gender of participants was not reported or could not be estimated in 15 studies. Females were a majority of the sample in 21 studies $(41 \%$ of studies that reported gender). Ethnicity was not reported in 38 studies. Majority white ethnicity was reported in 20 studies. Thus, eight studies reported white participants as being a minority of those represented. It can be tentatively suggested that teen cessation research needs to provide more demographic specifics (see Table Four). Such specifics are needed to discern variation in strength of effects as a function of gender or ethnicity [e.g., 43].

\section{Recruitment}

Means of Recruitment. Five studies failed to report any recruitment data, including means of recruitment (Table 5). Among those studies that did report means of recruitment, the most widely used form was person-to-person, which was employed in 16 studies. With person-to person recruitment, researchers utilized word of mouth to interest subjects in cessation clinics. Smokers were approached by researchers, staff, or other youth at lunch, in a smoking section, or at other locations (e.g., youth "hang-out" areas) during the day and were encouraged to bring friends or spread the word. The next most popular method, employed by 15 studies, offered monetary incentives or compensation (four of these studies made use of a monetary contest or lottery).

Twelve studies made use of PA announcements or classroom announcements. Eleven studies made use of screening as a means to recruit subjects. In this approach, a pool of subjects is examined through interview or file data. Those who are teen tobacco users are then asked directly to participate in 
a study. Ten studies made use of referrals. As defined by Sussman, Lichtman, Ritt, \& Pallonen [12], referrals are similar to person-to-person recruitment in that they involve approaching particular smokers and trying to interest them or their friends in a cessation clinic. However, a person-to-person approach involved an informal means of recruitment whereas referrals involved a "push" by an official for a youth to attend a clinic. Ten studies used flyers, and seven studies used newspaper advertisements. Six studies used posters, and six studies made use of class release time. Six studies used mandatory recruitment. Students were required to attend a tobacco program either to fulfill class requirements or to avoid suspension or other negative consequences $[30,54,77,82-83$, 89].

Five studies provided class credit, and five studies made use of TV or radio advertisements. Four studies involved presentations, in which a facilitator presented information about the project. Three studies involved assembly announcements; three studies involved policy enforcement to "place" people in a program; three studies involved administrative support; and one study each provided assistance with reminders, mentioned the program was free, or included a clinical interview (see Table 5). Multiple means of recruitment were utilized in 42 of the 61 studies that reported it.

Reach. Reach is defined as the number of participants who attend the first session relative to the number of adolescents notified. A total of 46 studies reported reach, or provided sufficient information such that it could be estimated, and among them a wide range exists. Reports of reach vary from six to $100 \%$, with a mean of approximately $61 \%$. (Reach data for studies that included mandatory attendance at programming was only available in three of six such studies and was a mean $=24 \%$ ).

In 16 studies, the whole unit was treated (e.g., classrooms, school systems) such that special recruitment efforts were not necessary and participation rates were very high (mean reach $=94 \%$ of 13 studies for which reach could be calculated; see Table 5). Eleven studies made use of screening techniques to identify smokers and potential participants. Screening occurred in contexts within which the intervention was telephone based (three studies), was within a medical clinic-type setting (five studies), or was in a university setting within which administrative files or survey responses of students were screened (three studies). The mean reach was equal to $65 \%$ across eight studies for which reach could be calculated (three of these eight studies also involved whole units but are not included in the previous calculation because they made use of a screening technique).

Generally reach is calculated in school-based clinics by calculating the percentage of smokers at the school who are enrolled as participants. The mean reach could be calculated at 21 of 28 school-clinics, and it was 34\%. Making brief classroom presentations by clinic facilitators seemed to show somewhat better reach (completed in five of these 21 studies, mean reach $=39 \%$ ), and offering money may have improved reach (completed in two of these 21 studies, mean reach $=74 \%$ ). Also, in the one study that reported it, principal encouragement led to an estimated reach of $40 \%$ of tobacco-using youths in the school [89]. Otherwise, reach did not appear to vary by type of recruitment method used in this school-based clinic context (see Table 5).

The nine studies with a reach of $15 \%$ or less were all school clinic-based, except for one very large Quit-and-Win study from Finland (3\%) and a system-wide school-based Quit-and-Win study (13\%). The mean number of tobacco users at baseline in the two Quit-and-Win contest studies was 3,241 and 331 . The average number of tobacco users served across all studies equals 659.5 mean baseline users times a mean reach of $61 \%$, which equals 402 subjects. Based on these overall mean data, the reach was small in these two studies, and the number of tobacco users served also was relatively small.

Of the remaining two studies in which reach was calculated, one was a hand-held computer study at a school context that relied mainly on person-to-person recruitment with some principal support (23\%) [22]. The other study was a medical clinic study that involved press releases, referrals and monetary payment $(53 \%)$ [80]. In summary, reach appears to be partly a function of intervention modality as opposed to type of strategy used, although there are strategies that might assist in maximizing reach within a context.

\section{Retention}

Posttest retention represents the percentage of tobacco users at the baseline first session that were present at the last posttest session immediately after involvement in the program and prior to follow-up data collection. Retention was not a planned statistic for 15 studies. These studies were either those that collected only pretest and follow-up data (six studies), those which made use of cross-sectional cohorts over time to assess effects of supply reduction trials, or those which involved system-wide modalities. Twelve studies failed to report retention. However, 10 of these studies did report follow-up statistics. The other two studies failed to provide any reach, retention, or follow-up statistics (see Table 5). These two studies did, however, provide quit-data [33, 85]. A total of 39 studies reported retention. The range was from $33-100 \%$, with a mean of $78 \%$. The highest retention rates were reported in the classroom-based programs (except for the Johnson et al. [35] study, at 36\%), and the lowest retention rates were reported in the school-based clinic programs.

\section{Follow-up}

The mean percentage of tobacco users at pretest who were present for follow-up was not reported in five studies, in which follow-up quit data were reported. Thus, for these studies, it is not clear who the subjects were that composed the quit-data. In a sixth study, follow-up data were collected but quit-rate information was not provided (odds ratios were provided [74]. In addition, follow-up data were not collected or reported in 14 studies. Of the 46 studies that did collect 
Table 5. Cessation studies - recruitment

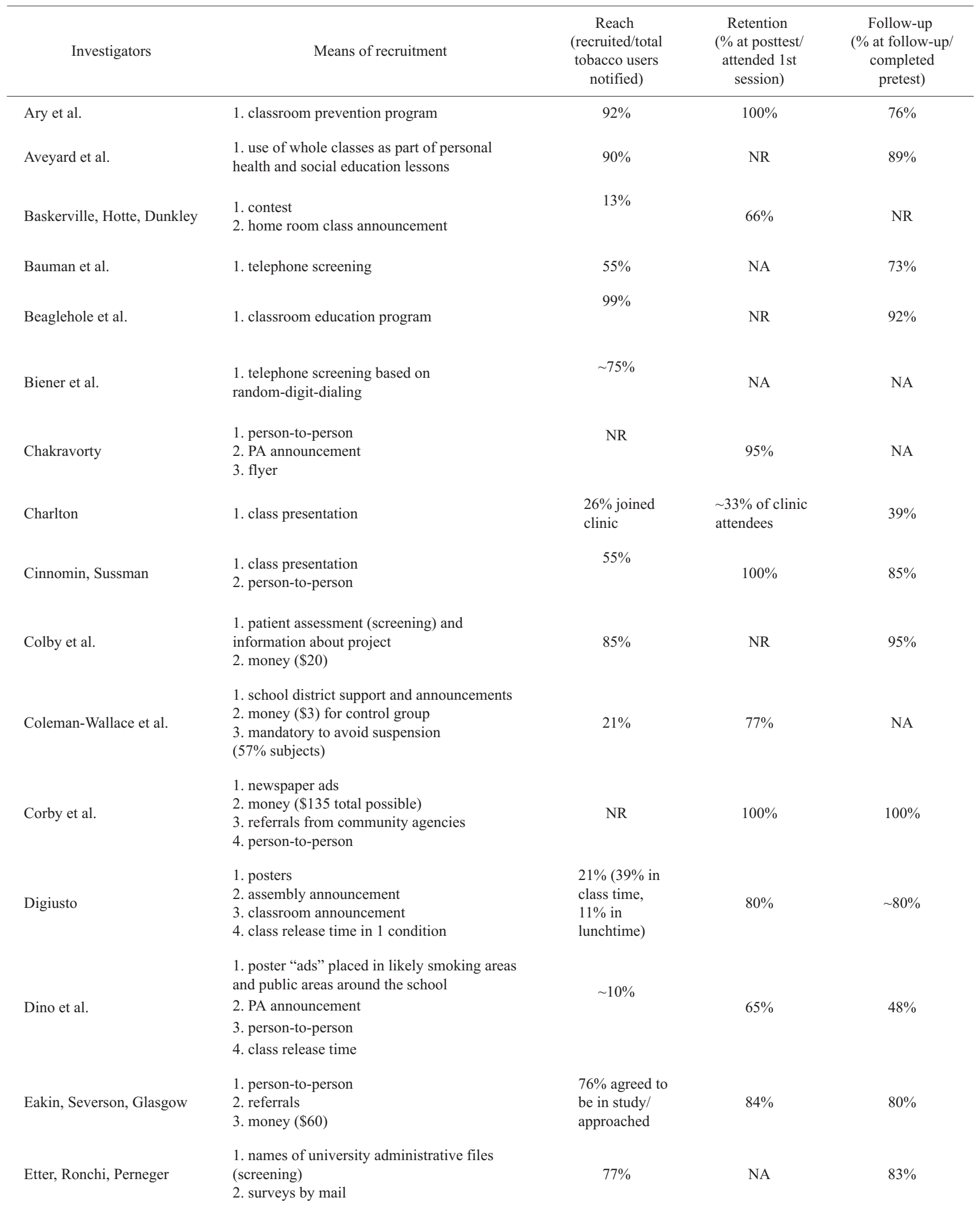


Table 5 (continued). Cessation studies - recruitment

\begin{tabular}{|c|c|c|c|c|}
\hline Investigators & Means of recruitment & $\begin{array}{l}\text { Reach } \\
\text { (recruited/total } \\
\text { tobacco users } \\
\text { notified) }\end{array}$ & $\begin{array}{l}\text { Retention } \\
(\% \text { at posttest } / \\
\text { attended } 1 \mathrm{st} \\
\text { session) }\end{array}$ & $\begin{array}{l}\text { Follow-up } \\
\text { (\% at follow-up/ } \\
\text { completed } \\
\text { pretest })\end{array}$ \\
\hline Fibkins & $\begin{array}{l}\text { 1. person-to-person } \\
\text { 2. referrals to school counselor and nurse }\end{array}$ & $9 \%$ & $100 \%$ & NA \\
\hline Forster et al. & $\begin{array}{l}\text { 1. classroom surveys (whole classes) } \\
\text { 2. media campaigns } \\
\text { 3. policy enactment and enforcement }\end{array}$ & $93 \%$ & NA & $93 \%$ \\
\hline Glasgow et al. & $\begin{array}{l}\text { 1. chart review/screening (approach subject at } \\
\text { contraceptive visit) } \\
\text { 2. money }(\$ 70)\end{array}$ & $\begin{array}{l}74 \% \text { agreed to be } \\
\text { in study/ } \\
\text { approached }\end{array}$ & NR & $91 \%$ \\
\hline Glover & 1. mandatory & NR & $100 \%$ & $100 \%$ \\
\hline Hafstad, Aaro, Langmark & $\begin{array}{l}\text { 1. county-wide mass media campaign } \\
\text { 2. home-mailed questionnaire, with three } \\
\text { reminders }\end{array}$ & NR & NA & $66 \%$ \\
\hline Horn et al. & $\begin{array}{l}\text { 1. poster "ads" placed in likely smoking areas } \\
\text { and public areas around the school } \\
\text { 2. PA announcement } \\
\text { 3. person-to-person } \\
\text { 4. class release time }\end{array}$ & $\sim 10 \%$ & $72 \%$ & NA \\
\hline Jason, Mollica, Ferrone & 1. classroom program & $\sim 100 \%$ & $\sim 100 \%$ & $84 \%$ \\
\hline Jerome & $\begin{array}{l}\text { 1. person-to-person } \\
\text { 2. referral by assistant principal }\end{array}$ & $\sim 23 \%$ & $88 \%$ & NA \\
\hline Johnson et al. & 1. classroom program & $\sim 100 \%$ & $36 \%$ & $17 \%$ \\
\hline Kempf, Stanley & In-patient facility - NA & $98 \%$ & NA & $77 \%$ \\
\hline Killen et al. & 1. classroom program & $\sim 100 \%$ & NR & $78 \%$ \\
\hline Lampkin & $\begin{array}{l}\text { 1. screened at school health center } \\
\text { 2. provider referral } \\
\text { 3. clinical interview } \\
\text { 4. } \$ 2500 \text { offered to participating sites }\end{array}$ & $42 \%$ & $\begin{array}{l}\mathrm{NR} \sim 68 \% \text { com- } \\
\text { pleted at least } 2 \\
\text { sessions }\end{array}$ & $69 \%$ \\
\hline Librett & $\begin{array}{l}\text { 1. posters } \\
\text { 2. flyers } \\
\text { 3. PA announcements } \\
\text { 4. person-to-person } \\
\text { 5. mandatory at } 1 \text { of } 5 \text { schools }\end{array}$ & $\sim 24 \%$ & $67 \%$ & NA \\
\hline
\end{tabular}


Table 5 (continued). Cessation studies - recruitment

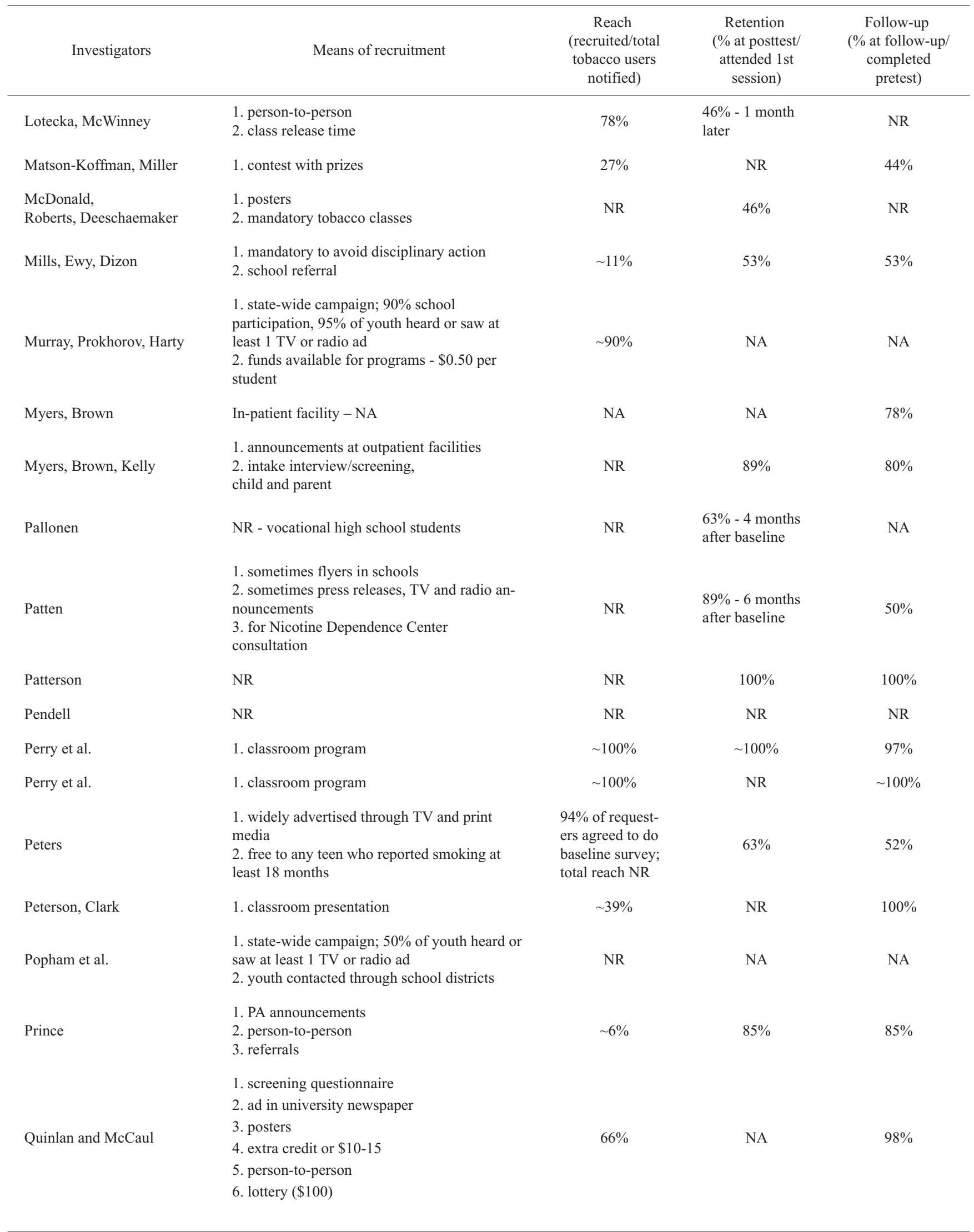


Table 5. (continued) Cessation studies - recruitment

\begin{tabular}{|c|c|c|c|c|}
\hline Investigators & Means of recruitment & $\begin{array}{l}\text { Reach } \\
\text { (recruited/total } \\
\text { tobacco users } \\
\text { notified) }\end{array}$ & $\begin{array}{l}\text { Retention } \\
\text { (\% at posttest/ } \\
\text { attended } 1 \mathrm{st} \\
\text { session) }\end{array}$ & $\begin{array}{l}\text { Follow-up } \\
\text { (\% at follow-up/ } \\
\text { completed } \\
\text { pretest })\end{array}$ \\
\hline Rigotti et al. & $\begin{array}{l}\text { 1. written information sent from health } \\
\text { departments } \\
\text { 2. minor sting operation }\end{array}$ & NR & NA & $\begin{array}{l}76 \% \text { annual } \\
\text { survey rate }\end{array}$ \\
\hline Smith et al. & $\begin{array}{l}\text { 1. flyers } \\
\text { 2. press releases } \\
\text { 3. referrals } \\
\text { 4. money }(\$ 50)\end{array}$ & $56 \%$ & $86 \%$ & $77 \%$ \\
\hline Sussman, Burton et al. & $\begin{array}{l}\text { 1. flyers } \\
\text { 2. PA announcements } \\
\text { 3. person-to-person } \\
\text { 4. class release time }\end{array}$ & $\sim 9 \%$ & $52 \%$ & $29 \%$ \\
\hline Sussman, Dent, Lichtman & $\begin{array}{l}\text { 1. classroom presentation } \\
\text { 2. elective class credit } \\
\text { 3. person-to-person } \\
\text { 4. class release time } \\
\text { 5. flyers }\end{array}$ & $34 \%$ & $54 \%$ & $51 \%$ \\
\hline Wakefield et al. & $\begin{array}{l}\text { 1. contacted school districts } \\
\text { 2. voluntary survey; strong } \\
\text { restrictions: } 57 \% \text { public places, } \\
48 \% \text { home, } 91 \% \text { school }\end{array}$ & $\begin{array}{l}80 \% \text { took annual } \\
\text { survey }\end{array}$ & NA & NA \\
\hline Weissman et al. & $\begin{array}{l}\text { 1. person-to-person } \\
\text { 2. voluntary - invitation }\end{array}$ & NR & $55 \%$ & $55 \%$ \\
\hline Zavela, Harrison, Owens & $\begin{array}{l}\text { 1. flyers } \\
\text { 2. PA announcements } \\
\text { 3. ads in college newspapers } \\
\text { 4. referrals } \\
\text { 5. money }(\$ 20)\end{array}$ & NR & $100 \%$ & $100 \%$ \\
\hline Zheng & $\begin{array}{l}\text { 1. school staff announcements at two schools } \\
\text { 2. money }(\$ 10)\end{array}$ & $72 \%$ & $98 \%$ & NA \\
\hline
\end{tabular}


follow-up data, the pretest-follow-up completion rate was an average of $75 \%$ (see Table 5). Generally, highest rates of follow-up were in studies with the smallest sample sizes. For example, of the 10 studies with follow-up rates of at least $90 \%$, sample sizes were under 100 for seven of them. The reasonably high retention and follow-up percentages indicate that cessation studies have fewer problems keeping subjects in the study than getting them enrolled. Future cessation studies possibly might best concentrate on improving reach.

Length of follow-up for the 52 studies that reported it was impressive with a mean of 8.6 months (see Table 6). Modal length of follow-up was six months (10 studies), 12 months (eight studies), three months (eight studies), five months (six studies), and one month (five studies). On average, studies exceeded the recommended adult cessation follow-up length of five months [92]. The six of eight studies with a follow-up of one month or less were pilot study clinics, in school-based or medical contexts (one was a mass media campaign and one was a smoke-free hospital study). The 15 studies with 12 months or greater follow-up included five classroom-based studies, three supply reduction studies, three communityscale studies, two medical-based clinics, one school-based clinic, and one family-based study.

\section{Outcomes}

This section reviews the outcomes of the 66 program studies. The main outcome measures are quit-rate and percentage reduction. Immediate quit-rate refers to percentage that reported quitting tobacco use, ideally for at least seven days at an immediate posttest (point prevalence abstinence), of those who attended the first session or were surveyed at baseline. An intent-to-treat approach was taken, in which those not measured at immediate posttest or at follow-up were assumed to still be using tobacco. Biochemical confirmation also was used when available. Percentage consumption reduction at immediate posttest refers to amount of reduction in tobacco use among those who did not quit at posttest. The specific statistic is the posttest level of tobacco use minus baseline level of tobacco use divided by baseline level of tobacco use. The quit-rate and percentage reduction measures are also reported at follow-up. These measures are estimated based on those who attended the first session, as well, and are calculated the same way as the immediate posttest measures.

Unfortunately, as with other data, cessation is not defined consistently. Generally, it is defined in a parallel manner to tobacco use (see Table 4). For example, if tobacco use is defined as use greater than once in the last week, cessation is defined as no use in the last week. In most studies that define tobacco use as daily use, cessation refers to no use in the last seven days or the last 30 days. (Quit results did not vary by this seven versus 30-day variation in quit-duration.) There were 16 studies in which subjects were reported to have quit tobacco but the definition of "tobacco cessation" provided is ambiguous. Four studies used the word "quit" and seemed to refer to no smoking on that day; these did use biochemical validation [18, 34, 41, 82]. Goldberg \& Gorn [54] used behavioral observation and seemed to be looking at continuous quitting. The subjects in one study were asked simply "Do you smoke cigarettes?" and two other studies mentioned that "quitting" was assessed without describing the specific assessment used $[45,64,89]$. Finally, eight studies reported cessation if the number of cigarettes smoked per day at posttest or follow-up was $0[13,32,39,49,79,83,85,90]$.

The order of presentation of results is as follows. First, the overall level of baseline tobacco use among this sample is considered. Second, overall measures of control group cessation and reduction are estimated. Third, overall program condition cessation measures are considered. Fourth, cessation is considered as a function of program theory and modality. Fifth, cessation is considered as a function of number of program sessions. Sixth, the most effective and methodologically rigorous programs are identified. Finally, seventh, variation in effectiveness is explored as a function of gender, ethnicity, age range, and baseline tobacco use by examining the most effective program subgroup $(n=34)$, against the full group of programs $(n=66)$.

Baseline Tobacco Use. Level of tobacco use was defined as greater than one cigarette per week in seven studies, greater than one cigarette per month in seven studies, and simply as "current smoking" and greater than 100 lifetime cigarettes in one study. However, level of tobacco use was defined in most studies as daily use. Specifically, it was defined as at least one cigarette per day in $71 \%(n=40)$ of the 56 studies that reported it (see Table 4). Specifically, it was defined as greater than one cigarette (or dip) per day in five studies. Also, it was defined as two to four cigarettes per day in three studies, five to nine cigarettes per day in 10 studies, $10-14$ cigarettes per day in 13 studies, 15-19 cigarettes per day in seven studies, and 20 or greater cigarettes per day in three studies.

In the program studies in general, the subjects were fairly heavy smokers. An approximate grand mean of 8.4 cigarettes per day is estimated for baseline use. This mean was calculated by giving a value of once every 30 days or more a value of .033 cigarettes per day, once every seven days or more a value of .14 cigarettes per day, and current smoking a value of .14 cigarettes per day. (The estimate that current smoking is .14 may be an underestimate or an overestimate.) In addition, "greater than" statistics were estimated as being "equal to" measures. This variation in baseline tobacco use is troublesome but by making these few assumptions, one obtains a general idea of range and mean of tobacco use in cigarette per day units.

Consideration of Control Group Cessation and Consumption Reduction Rates. Cessation (quit) rates for the intervention studies need to be compared to cessation rates of those at comparable baseline levels of tobacco use, who have not received the programming. A strong comparison is one in which subjects can be compared directly to a randomly assigned or matched control group. That is, a control group that is measured at the same time-points as the program and that has the same baseline characteristics as the program group 
Table 6. Cessation studies-outcomes

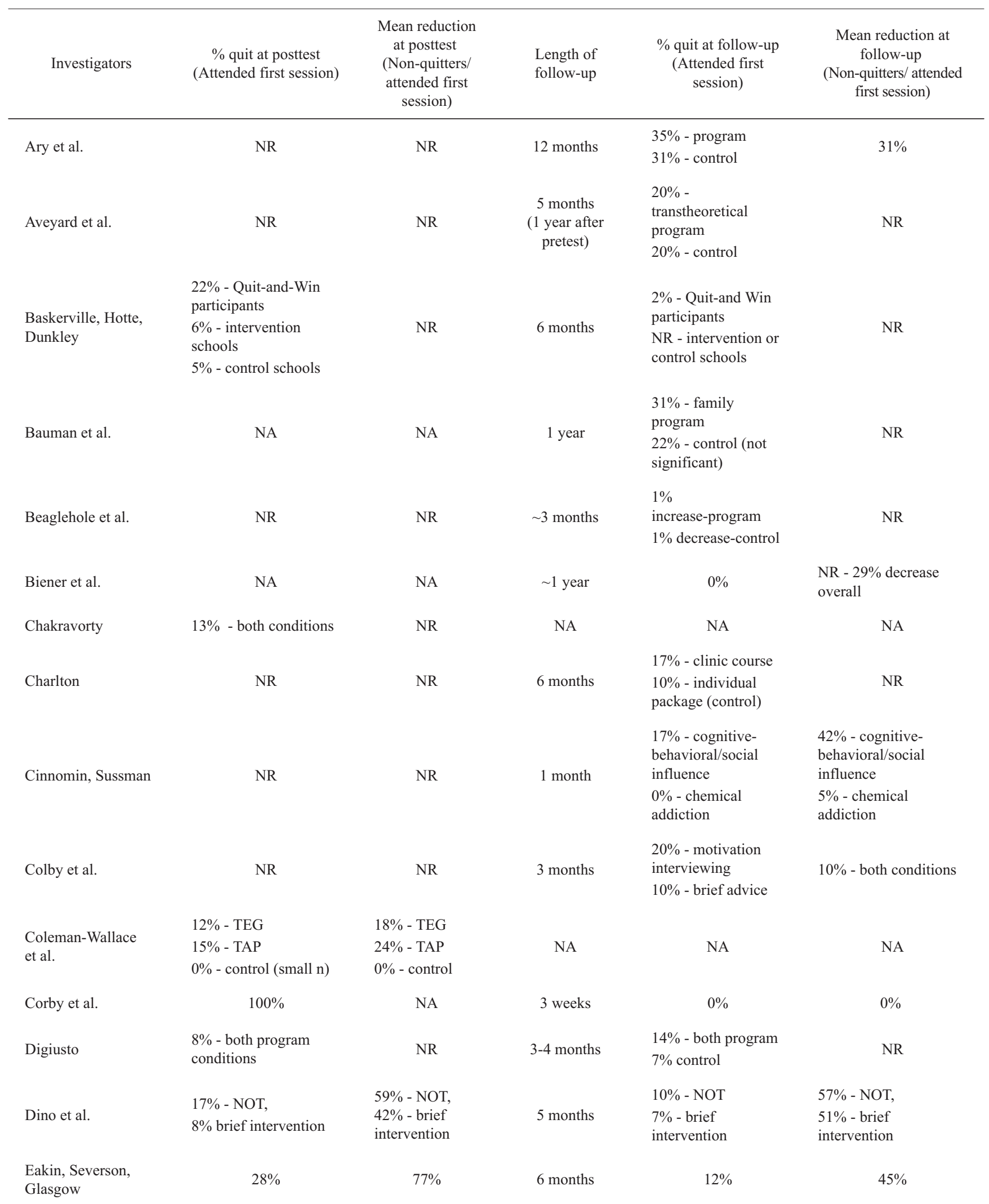


Table 6 (continued). Cessation studies-outcomes

\begin{tabular}{|c|c|c|c|c|c|}
\hline Investigators & $\begin{array}{c}\% \text { quit at posttest } \\
\text { (Attended first session) }\end{array}$ & $\begin{array}{l}\text { Mean reduction } \\
\text { at posttest } \\
\text { (Non-quitters/ } \\
\text { attended first } \\
\text { session) }\end{array}$ & $\begin{array}{l}\text { Length of } \\
\text { follow-up }\end{array}$ & $\begin{array}{l}\% \text { quit at follow-up } \\
\text { (Attended first } \\
\text { session) }\end{array}$ & $\begin{array}{l}\text { Mean reduction at } \\
\text { follow-up } \\
\text { (Non-quitters/ attended } \\
\text { first session) }\end{array}$ \\
\hline $\begin{array}{l}\text { Etter, Ronchi, } \\
\text { Perneger }\end{array}$ & NA & NA & $\begin{array}{l}7 \text { months after } \\
\text { baseline }\end{array}$ & $\begin{array}{l}0 \% \text { - both program } \\
\text { and control } \\
\text { conditions }\end{array}$ & $\begin{array}{l}3 \% \text { increase in pro- } \\
\text { gram, } 5 \% \text { increase in } \\
\text { control }\end{array}$ \\
\hline Forster et al. & NA & NA & 36 months & $\begin{array}{l}2 \% \text { increase } \\
\text { program } \\
7 \% \text { increase control }\end{array}$ & $6 \%$ relative reduction \\
\hline Glasgow et al. & NR & NR & 6 months & $\begin{array}{l}10 \% \text { program } \\
6 \% \text { control }\end{array}$ & NR \\
\hline Greenberg, Deputat & $\begin{array}{l}40 \% \text { - fear } \\
27 \% \text { - facts } \\
36 \% \text { - values } \\
6 \% \text { - control }\end{array}$ & NR & 5 months & $\begin{array}{l}12 \% \text { - fear } \\
16 \% \text { - facts } \\
24 \% \text { - values } \\
4 \% \text { - control }\end{array}$ & NR \\
\hline $\begin{array}{l}\text { Hafstad, Aaro, } \\
\text { Langmark }\end{array}$ & NR & NR & $\begin{array}{l}2 \text { weeks } \\
\text { (5 weeks } \\
\text { since start } \\
\text { of campaign) }\end{array}$ & $12 \%$ & NR \\
\hline Horn et al. & $\begin{array}{l}14 \% \text { - NOT, } 4 \% \text { brief } \\
\text { intervention }\end{array}$ & $\begin{array}{l}76 \% \text { - NOT, } \\
54 \% \text {-brief } \\
\text { intervention }\end{array}$ & NA & NA & NA \\
\hline Hurt et al. & $11 \%$ & $\sim 49 \%$ & 6 months & $5 \%$ & $\sim 19 \%$ \\
\hline $\begin{array}{l}\text { Jason, Mollica, } \\
\text { Ferrone }\end{array}$ & $\begin{array}{l}55 \% \text { - both program } \\
\text { groups } \\
0 \% \text { - control group }\end{array}$ & $\begin{array}{l}14 \% \text { - both pro- } \\
\text { gram groups } \\
50 \% \text { - control }\end{array}$ & 17 months & $\begin{array}{l}41 \% \text { - both program } \\
\text { groups } \\
0 \% \text { - control }\end{array}$ & $\begin{array}{l}0 \% \text { - both program } \\
\text { groups } \\
400 \% \text { increase-control }\end{array}$ \\
\hline Jerome & $29 \%$ & $41 \%$ & NA & NA & NA \\
\hline Johnson et al. & $0 \%$ for all groups & NR & 24 months & $0 \%$ for all groups & NR \\
\hline Kempf, Stanley & NA & NA & 2 weeks & $\begin{array}{l}\text { NR - "as-if" } 100 \% \\
\text { in smoke-free pro- } \\
\text { gram but not stated }\end{array}$ & NR \\
\hline Killen et al. & NR & NR & 2 months & $\begin{array}{l}4 \% \text { - program } \\
9 \% \text { - control }\end{array}$ & NR \\
\hline Lampkin & NR & NR & $\sim 5$ months & $14 \%$ & $18 \%$ \\
\hline Librett & $17 \%$ & $39 \%$ & NA & NA & NA \\
\hline
\end{tabular}


Table 6 (continued). Cessation studies-outcomes

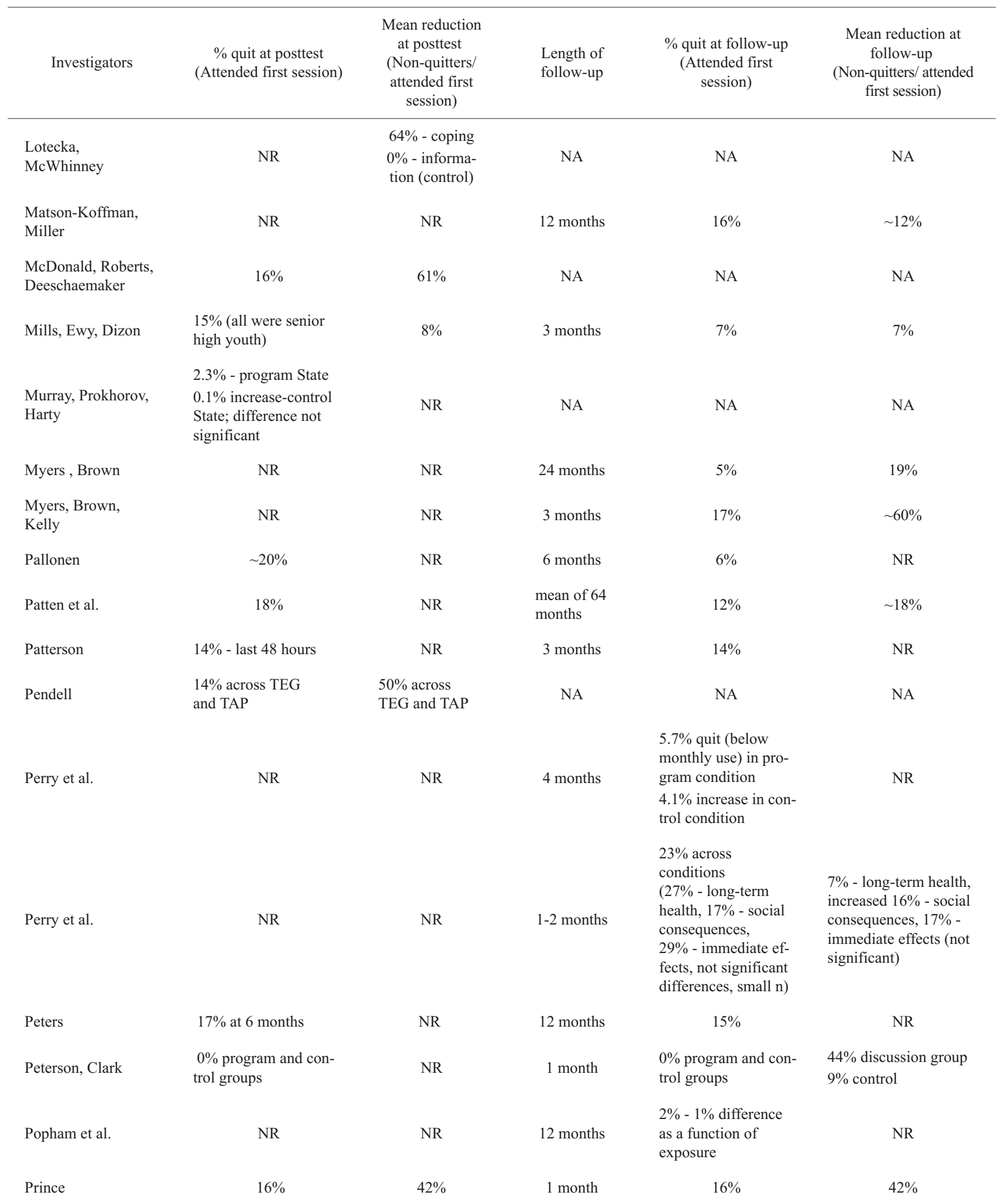


Table 6 (continued). Cessation studies-outcomes

\begin{tabular}{|c|c|c|c|c|c|}
\hline Investigators & $\begin{array}{c}\% \text { quit at posttest } \\
\text { (Attended first session) }\end{array}$ & $\begin{array}{l}\text { Mean reduction } \\
\text { at posttest } \\
\text { (Non-quitters/ } \\
\text { attended first } \\
\text { session) }\end{array}$ & $\begin{array}{l}\text { Length of } \\
\text { follow-up }\end{array}$ & $\begin{array}{l}\% \text { quit at follow-up } \\
\text { (Attended first } \\
\text { session) }\end{array}$ & $\begin{array}{l}\text { Mean reduction at } \\
\text { follow-up } \\
\text { (Non-quitters/ attended } \\
\text { first session) }\end{array}$ \\
\hline Quinlan, McCaul & NA & NA & 1 month & $\begin{array}{l}3 \% \text { - stage matched } \\
14 \% \text { - stage } \\
\text { mismatched } \\
0 \% \text { - control }\end{array}$ & NR \\
\hline Rigotti et al. & $\begin{array}{l}0 \% \text { - program } \\
1 \% \text { - control }\end{array}$ & NR & $\begin{array}{l}24 \text { months- } \\
\text { anonymous } \\
\text { surveys }\end{array}$ & $\begin{array}{l}3 \% \text { increase- } \\
\text { program } \\
0 \% \text { - control }\end{array}$ & NR \\
\hline $\begin{array}{l}\text { Skjoldebrand, } \\
\text { Gahnberg }\end{array}$ & $\sim 4 \%$ & NR & NA & NA & NA \\
\hline Suedfeld et al. & NA & NA & 3 months & $0 \%$ & $\begin{array}{l}\text { Sensory D-Message } \\
28 \% \\
\text { Sensory D-No Message } \\
22 \% \\
\text { No Sensory D-Message } \\
22 \% \\
\text { Control } 0 \%\end{array}$ \\
\hline $\begin{array}{l}\text { Sussman, Burton } \\
\text { et al. }\end{array}$ & $\begin{array}{l}35 \% \text { - chemical addition- } \\
\text { ST } \\
11 \% \text { - chemical } \\
\text { addiction - smoking } \\
24 \% \text { - psychosocial } \\
\text { dependency - ST } \\
26 \% \text { - psychosocial } \\
\text { dependency - smoking } \\
8 \% \text { - wait-list control- } \\
\text { smoking }\end{array}$ & NR & 3 months & $\begin{array}{l}15 \% \text { - program condi- } \\
\text { tions - ST } \\
7 \% \text { - program condi- } \\
\text { tions - smoking } \\
0 \% \text { - wait list control- } \\
\text { ST } \\
8 \% \text { - wait list control } \\
\text { - smoking }\end{array}$ & NR \\
\hline $\begin{array}{l}\text { Sussman, Dent, } \\
\text { Lichtman }\end{array}$ & $\begin{array}{l}\text { 14\% - both program } \\
\text { conditions } \\
\text { NA - control }\end{array}$ & $\begin{array}{l}23 \% \text { - both pro- } \\
\text { gram conditions } \\
\text { NA - control }\end{array}$ & 4-5 months & $\begin{array}{l}17 \% \text { - both program } \\
\text { conditions } \\
8 \% \text { - control }\end{array}$ & $23 \%$ - in all conditions \\
\hline $\begin{array}{l}\text { Sussman, Dent, } \\
\text { Stacy }\end{array}$ & NR & NR & 12 months & $\begin{array}{l}34 \% \text { - health educator } \\
21 \% \text { - self-instruction } \\
21 \% \text { - control }\end{array}$ & $\begin{array}{l}15 \% \text { - health educator } \\
0 \% \text { - self-instruction } \\
\text { and control }\end{array}$ \\
\hline Townsend et al. & $\begin{array}{l}60 \% \text { - agreed to try to } \\
\text { quit NA }\end{array}$ & NA & NA & NA & NA \\
\hline Vartiainen et al. & NA & NA & 6 months & $28 \%$ & NR \\
\hline Wakefield et al. & NA & NA & $\sim 24$ months & $\begin{array}{l}\text { Odds ratios } \\
\text { Public place } .90 \\
\text { Home ban } .78 \\
\text { Enforce school ban } \\
.89\end{array}$ & NA \\
\hline Weisman et al. & $36 \%$ & $25 \%$ & 5 months & $36 \%$ & NR \\
\hline
\end{tabular}


Table 6 (continued). Cessation studies-outcomes

\begin{tabular}{|c|c|c|c|c|c|}
\hline Investigators & $\begin{array}{c}\% \text { quit at posttest } \\
\text { (Attended first session) }\end{array}$ & $\begin{array}{l}\text { Mean reduction } \\
\text { at posttest } \\
\text { (Non-quitters/ } \\
\text { attended first } \\
\text { session) }\end{array}$ & $\begin{array}{l}\text { Length of } \\
\text { follow-up }\end{array}$ & $\begin{array}{c}\% \text { quit at follow-up } \\
\text { (Attended first } \\
\text { session) }\end{array}$ & $\begin{array}{l}\text { Mean reduction at } \\
\text { follow-up } \\
\text { (Non-quitters/ attended } \\
\text { first session) }\end{array}$ \\
\hline $\begin{array}{l}\text { Zavela, Harrison, } \\
\text { Owens }\end{array}$ & NR & NR & 1 month & NR & $\begin{array}{l}\text { mean days abstinent } \\
\text { mint snuff - } 18.8(63 \% \\
\text { of month) } \\
\text { bubble gum }-21.5 \\
\text { ( } 72 \% \text { of month) } \\
\text { No substitute }-23.5 \\
\text { ( } 78 \% \text { of month) }\end{array}$ \\
\hline Zheng & $\begin{array}{l}13 \% 7 \text {-day quit rate } \\
4 \% 30 \text {-day quit rate }\end{array}$ & $20 \%$ & NA & NA & NA \\
\hline
\end{tabular}

$\mathrm{NA}=$ not applicable; $\mathrm{NR}=$ not reported; $\sim=$ approximately

(i.e., in demographic composition and baseline tobacco use). The ideal comparison would be random assignment to a control group; however, when not practical, design modifications and statistical techniques can help control for possible third variable confounds [see 26].

One other means to provide a control quit rate would be to establish an overall quit rate at a given level of tobacco use, assuming minimal program exposure. One might plot naturally occurring quit-rate as a function of baseline level of tobacco use in prospective studies. This quit-rate is likely to fluctuate over time and location, but it may be better than no use of a control quit statistic at all. Alternatively, this overall quit-rate can be determined by averaging quit-rates across all control groups in studies that do provide quasi-experimental or experimental designs. This latter type of control group quit-rate was calculated for the present review. While only a minority of the studies utilized control groups, those that did included control groups similar to the program groups, i.e., from a similar population with equivalent levels of baseline tobacco use.

Control group cessation rates at follow-up ranged from 0 to $31 \%$ in the 23 program studies that reported it (mean = $7.2 \%$ ). Of these 23 studies, the breakdown of control group quit-rates is as follows. Eight studies report $0 \%$, two studies report $1 \%$, one study reports $4 \%$, one study reports $6 \%$, two studies report $7 \%$, two studies report $8 \%$, one study reports $9 \%$, two studies report $10 \%$, and one study each reports $10 \%, 20 \%$, $21 \%, 22 \%$, and $31 \%$.

For three of four studies which reported a control group cessation rate of $20 \%$ or greater, baseline smoking was defined as greater than one cigarette in the last month (one study) or in the last week (two studies). Smokers were relatively young in these studies compared to other program studies. (Without those three studies composed of "light smokers" the mean cessation rate would be 5\%). Thus, a control group quit rate of $7 \%$ could be considered a reasonable (even liberal) proxy for cessation in the program studies for which mean baseline smoking is at least one cigarette per day, and is a mean of approximately eight cigarettes per day, at three-to- 12 months follow-up. Immediate post-program quit-rates in control groups unfortunately were reported in only 12 studies. Examining control group quit rates at follow-up, and using immediate quit-rate as a proxy if follow-up quit rate is missing (which in theory should not differ since little or no programming is offered), the mean cessation rate is $6.5 \%(\mathrm{n}=26$ studies). Data is presented with and without use of this proxy measure in Tables 7 and 8.

In several studies no one quit in the control group, whereas in other studies quit- rates hover around $7 \%$ or slightly higher. Zero quit rates in control groups generally occurred in classroom-based or system-wide modality studies (the Ary et al. study [31] is an exception, with a $31 \%$ control group quit-rate), whereas higher control group quit rates occurred in clinic studies. Those in clinic control groups generally were either on a wait-list for participation in the program, or were provided with minimal information to support cessation. One may infer that persons who are more motivated to quit - and hence seek assistance at a clinic - show higher quit-rates in a control condition. Still, as a single estimate, a 7\% control group quit rate can be used as a proxy across immediate posttest and follow-up time-points.

Percentage reduction in amount of tobacco used control group statistics were only reported in seven studies at immediate posttest, and eight studies at follow-up. Using the follow-up measures, and using immediate posttest data as a proxy for missing data at follow-up, these data are reported in 12 studies (overall mean reduction $=10.9 \%$ ). Rates reported were $0 \%$ reduction in five studies, $400 \%$ increase in one study (Jason and colleagues (1982), over a 17-month period among a very small sample of 14-16 year olds) and a 5\% increase in another study (increases are assumed to be treated as $0 \%$ reduction). Also, rates were 3\% reduction in one study, a $9 \%$ reduction in one study, a $23 \%$ reduction in one study, a $42 \%$ 
Table 7. Follow-up outcomes of the 66 studies as a function of theory

\begin{tabular}{|c|c|c|c|c|c|}
\hline Theory & \# studies & Quit \% (\#s) & Quit $2 \%(\# \mathrm{~s})$ & $\%$ reduct $(\# \mathrm{~s})$ & $\%$ reduct $2(\# \mathrm{~s})$ \\
\hline Motivation enhancement & 9 & $19(8)$ & $18(9)$ & $27(4)$ & - \\
\hline Contingency-based reinforced & 5 & $16(5)$ & - & $6(2)$ & $13(3)$ \\
\hline Social influences & 11 & $12(10)$ & - & $27(5)$ & - \\
\hline Cognitive behavioral & 16 & $11(12)$ & $11(15)$ & $32(6)$ & $44(10)$ \\
\hline Stage of change & 7 & $11(5)$ & $12(7)$ & $13(2)$ & $24(4)$ \\
\hline Affect-oriented & 2 & $9(2)$ & - & $23(1)$ & - \\
\hline Addiction/recovery & 9 & $5(3)$ & $12(9)$ & $42(4)$ & $43(7)$ \\
\hline Supply reduction & 7 & $0(4)$ & $0(5)$ & $15(2)$ & - \\
\hline
\end{tabular}

Quit \% (\#s) = \% quit at follow-up (\# studies that provided data); Quit 2\% (\#s) = \% quit at follow-up, and immediate posttest quit rates used if data is missing (\# studies that provided data); \% reduct $(\# \mathrm{~s})=\%$ reduction among non-quitters, at follow-up (\# studies that provided data); \% reduct 2 (\#s) $=\%$ reduction among non-quitters at follow-up, and immediate posttest percentage reduction rates used if data is missing (\# studies that provided data).

reduction in one study, and a $54 \%$ reduction in one study. As a rough, conservative rule of thumb, we can expect a percentage reduction in a control group from immediate posttest to 12 months later of $11 \%$, particularly if offered any minimal programming. If no programming is offered, among teens it is reasonable to expect no reduction. Rather, as these teens grow older, amount of tobacco consumed is expected to increase [27].

Overall Program Quit Rates and Reduction. A total of 19 studies failed to report immediate program quit rates (i.e., right after the end of a program; generally a couple of weeks post-baseline) and 34 studies failed to report percentage reduction at immediate posttest. In addition, 10 studies did not plan to report immediate quit rates or percentage reduction by design; rather they were looking for a cumulative effect of exposure to a program or campaign over a long period of time (supply reduction or several system-wide efforts). Of the 37 studies that reported immediate program quit rates, the mean quit rate at posttest for program groups was $17.5 \%$ (range $=0$ to $100 \%)$.

There were two studies with very high quit-rates and very small sample sizes. One contingency-based reinforcement study achieved $100 \%$ cessation with a sample size of eight subjects [63], which dropped off to $0 \%$ at follow-up. A second, classroom-based study $(n=32)$ achieved an immediate post-program quit rate of 55\% [34]. Other than these two studies, the highest immediate post-program quit-rate was at 34\%. A recalculation of average immediate quit rate, removing these two studies is $14.1 \%(\mathrm{n}=35$ studies $)$. Essentially, it would appear that teen cessation programs can double immediate quit rates compared to a control condition $(14 \%$ versus $7 \%)$.

Table 8. Follow-up outcomes of the 66 studies as a function of modality

\begin{tabular}{|c|c|c|c|c|c|}
\hline Modality & \# studies & Quit \% (\#s) & Quit 2\% (\#s) & $\%$ reduct $(\# \mathrm{~s})$ & $\%$ reduct $2(\# \mathrm{~s})$ \\
\hline Medical/recovery clinics & 13 & $10(9)$ & $10(11)$ & $27(8)$ & $14(9)$ \\
\hline Family & 1 & 31 & - & 9 & - \\
\hline Computer & 3 & $13(2)$ & $18(3)$ & - & $41(1)$ \\
\hline Sensory deprivation & 1 & 0 & - & 24 & - \\
\hline
\end{tabular}

Quit \% (\#s) = \% quit at follow-up (\# studies that provided data); Quit 2\% (\#s) = \% quit at follow-up, and immediate posttest quit rates used if data is missing (\# studies that provided data). 
Of the 21 studies that did report immediate posttest percentage consumption reduction, mean percentage reduction was $42.6 \%$ with a very wide range across studies (range $=7 \%$ to $93 \%$ ). Still, this is higher than a $0-11 \%$ control group range. Very tentatively, it would seem that programs quadruple percentage reduction compared to a control (43\% versus $11 \%$ ).

A total of 48 studies reported program quit rates at follow-up. Of the 48 studies that did provide data, an overall quit rate at time of follow-up was a mean of $11.5 \%$ (range $=$ $0-41 \%$; the highest quit rate was in the study by Jason and colleagues [34]. Arguably, maintenance of program effects is achieved in teen cessation studies ( $12 \%$ versus $7 \%$ ), with a near doubling of cessation relative to controls. An examination of the six programs that required mandatory attendance revealed a mean quit-rate of $11 \%$, which is about the same as the overall mean quit rate at follow-up.

Only $2 \%$ lower cessation overall was found at follow-up compared to immediate post-program). This result would tend to suggest that relapse rates in teen cessation studies tend to be low (15\%). However, examining the 22 programs that provide quit-rate data at both immediate post-program and follow-up time-points (mean $=8.4$ months follow-up), reveals a more conservative $36 \%$ relapse rate. Still, this relapse rate is much lower than with adults, which is as high as $70 \%$ over a similar time duration $[27,92]$.

Of the 24 studies that did provide program percentage consumption reduction data at follow-up, the mean reduction rate was $25.8 \%$ (range $=0$ to $60 \%$ ). Arguably, it would seem that programs can double percentage reduction compared to a control at follow-up ( $26 \%$ versus $11 \%$ ). For outcome data, see (see Table 6).

Outcomes As A Function of Theory or Modality. Differences in cessation rates as a function of theory or modality of programming is shown in Tables 7 and 8. Regarding theory-based quit-rates at follow-up, above the grand program cessation mean of $12 \%$ are the motivation enhancement $(19 \%)$ and contingency-based reinforcement $(16 \%)$ programs. Programs that involve manipulation of intrinsic or extrinsic motivation do the best at changing behavior over a three to 12 month follow-up period. Programs that achieved the lowest quit-rates were supply reduction $(0 \%)$ and addiction/recovery-based (5\%). Apparently, more impersonal programs (supply reduction), or programs that relied on use of pharmacological adjuncts or recovery from addiction themes did not work as well with teen smokers in these set of studies. Regarding percentage reduction, however, addiction/recovery-based programs, achieved relatively good results $(42 \%$; above the grand program percentage reduction mean of $26 \%$ ).

Regarding program modality, classroom-based programs achieved the best quit-rates (17\%). Expert system/ computer-type programs (tailored self-help) also achieved high quit-rates relative to the grand program quit-rate $(13 \%)$. Programming that was implemented system wide $(6 \%)$, at medical-based clinics $(10 \%)$ and in sensory deprivation chamber (university lab; one study, $0 \%$ quit-rate) all did relatively poorly. Programs delivered in school-based clinics (34\%) and medical/recovery clinics (27\%) achieved the highest percentage reductions, while other modalities did relatively poorly. Possibly, a clinic-based environment is able to encourage decreases in level of tobacco use, if not total quitting. The system-wide programs, while involving relatively more subjects, did not demonstrate a stronger overall effect (i.e., a weaker effect, but on more subjects) than did other modalities. The Wakefield et al. study [74] may provide an exception in that a $10-20 \%$ reduction in the odds of smoking was found over a very large population when access reduction was enforced; however, no quit data were provided.

One caveat with these comparisons is that they are made against a grand program mean (12\%). Of course, if compared against a grand control-group mean (7\%), several of these programs would seem to have tripled quit rates. A superior comparison would be to aggregate data across within-study program minus control group differences. There were far too few data points to present this analysis.

However, a few of the theory or modality sets do provide some information in this regard. For the motivation enhancement studies, the average program quit-rate minus the grand control quit rate mean of $7 \%$ is equal to $11 \%$ at follow-up. Data were available from four studies that provided program minus control group quit-rate, within-study comparisons. The average difference achieved across these studies was $8 \%$ and, if data from five studies is used (one data point from immediate posttest as a proxy), of $10 \%$.

For the supply reduction studies, the average program quit-rate minus the grand control quit rate mean of $7 \%$ is equal to $-6 \%$ at follow-up. Data were available from three studies that provided program minus control group quit-rate, within-study comparisons. A difference of $1 \%$ favoring the program condition was achieved involving three studies.

For the classroom modality programs, the average program quit-rate minus the grand control quit rate mean is equal to $10 \%$ at follow-up. Data were available from seven studies that provided program minus control group quit-rate, within-study comparisons. These studies also revealed a difference of $10 \%$.

Likewise, a 5\% difference would be expected across school clinic programs, and these exact results were achieved, involving nine studies in the program minus control group direct-comparisons. Thus, it seems that the results presented show promise in terms of accuracy.

Program Outcomes As A Function of Number of Sessions. Another question is whether program results vary as a function of number of sessions. Number of sessions was not indicated in two programs. For programs in which there were no sessions involved (15 programs; e.g., media or policy interventions), the follow-up quit rate was $8 \%$ and the percentage reduction was $12 \%$. Where one to four sessions were delivered (17 programs), the follow-up quit-rate was 9\% (based on 15 program data points) and the percentage reduction was 33\% (based on eight program data points). Where five to eight 
Table 9. Standard of evidence of effectiveness: examining the 34 programs with the highest quit-rates

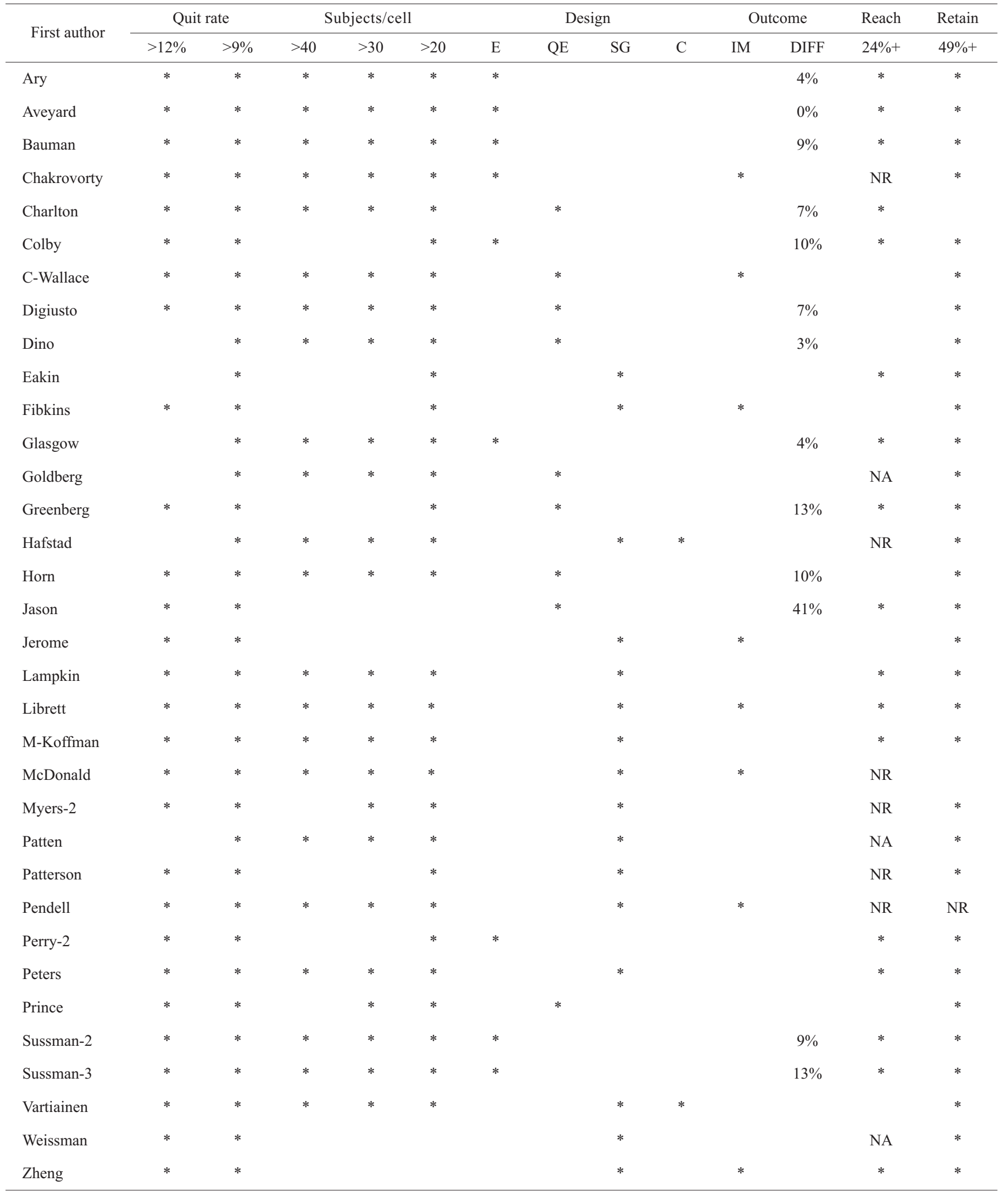

$*=$ meets this criterion; $\mathrm{NA}=$ not applicable; $\mathrm{NR}=$ not reported; $\mathrm{E}=$ experimental design $; \mathrm{QE}=$ quasi-experimental design; $\mathrm{S}=$ single - subject design; $\mathrm{C}=$ community-wide type study; IM = use of an immediate outcome proxy; DIFF = whether or not and how much difference was observed between a program and a control group; += or more. 


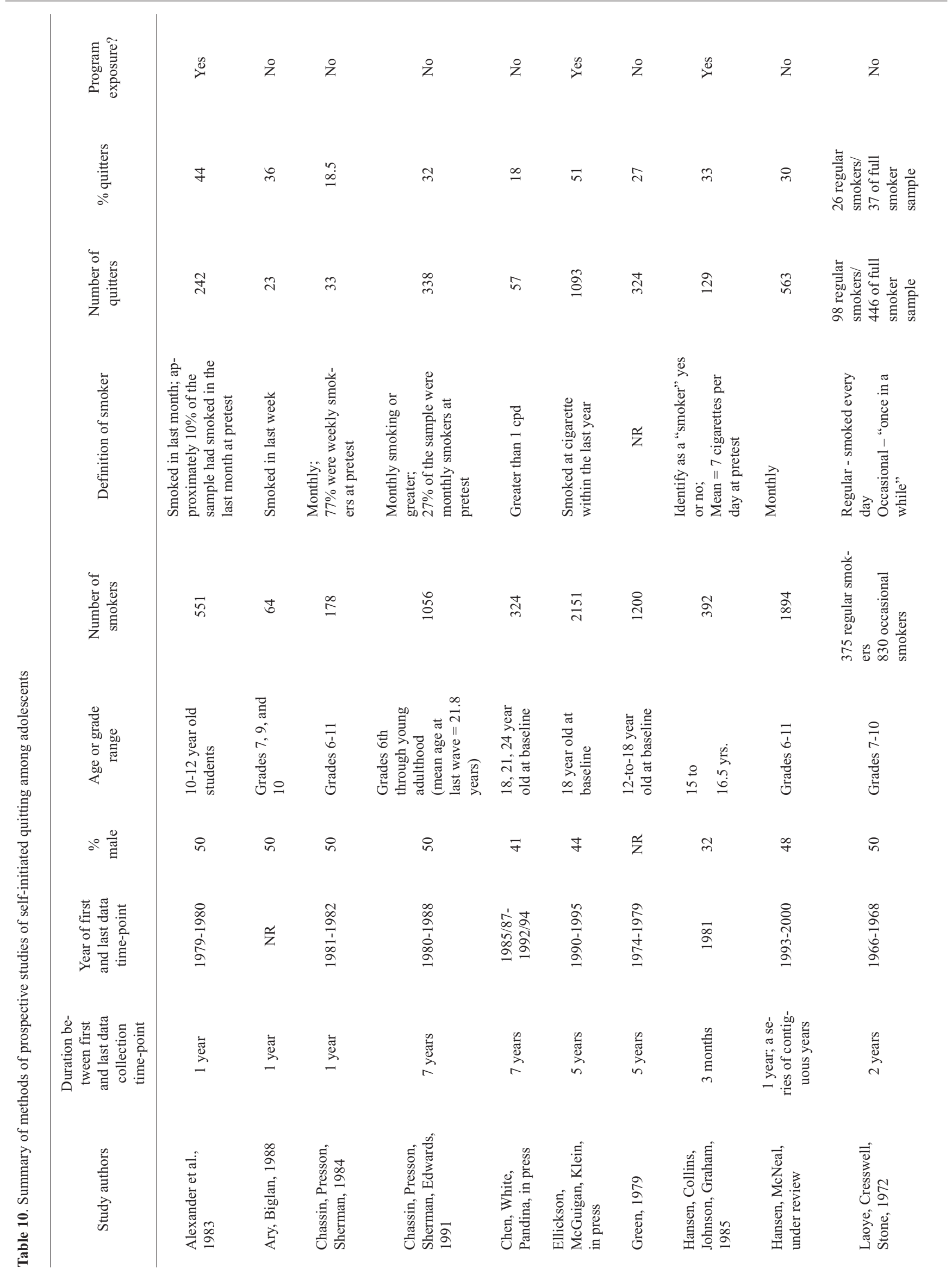




\begin{tabular}{|c|c|c|c|c|c|c|}
\hline 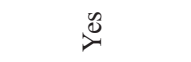 & $\stackrel{\circ}{z}$ & z & z & $\stackrel{\infty}{\infty}$ & $\stackrel{\infty}{2}$ & z \\
\hline 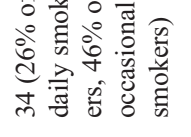 & ते & $\cong$ & $\bar{\sigma}$ & n & $\bar{\lambda}$ & $\stackrel{\circ}{-}$ \\
\hline t & $\stackrel{\imath}{ }$ & ๙ & $\stackrel{\circ}{0}$ & $\underset{\sim}{\sim}$ & $\dddot{\cong}$ & aे \\
\hline
\end{tabular}
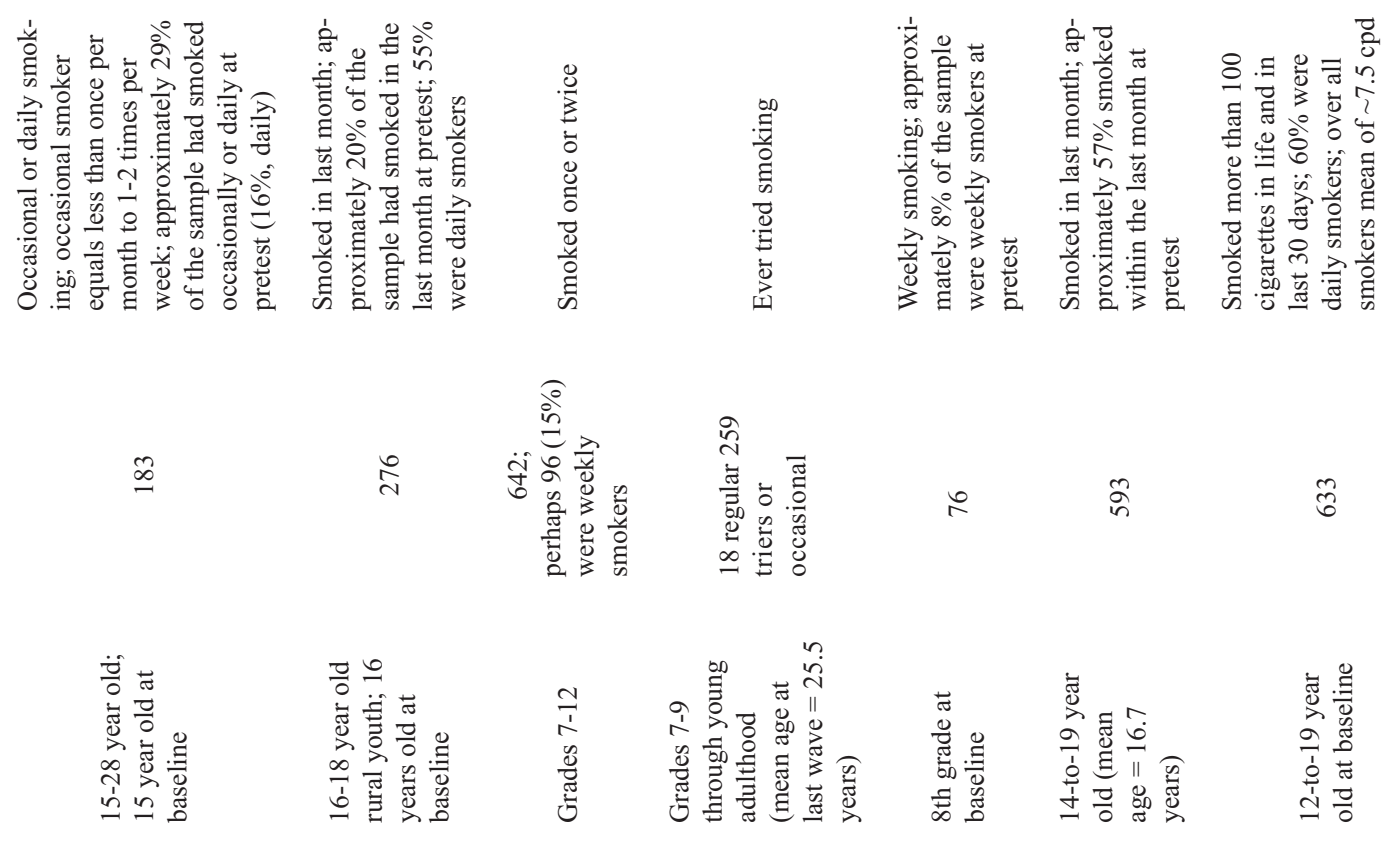
q
$\stackrel{\infty}{n}$
in
ลิ
in
in
$n$
$\frac{2}{a}$

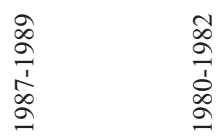
$\infty$
2
$\frac{1}{b}$
$\frac{1}{2}$
$\frac{2}{\frac{2}{2}} \quad \frac{n}{\frac{a}{2}}$
$\frac{n}{2}$
$\stackrel{\alpha}{a}$

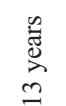

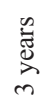

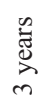

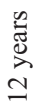

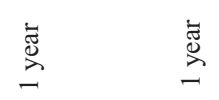

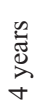

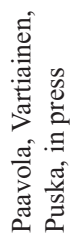

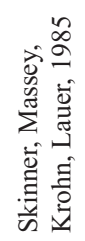

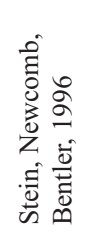

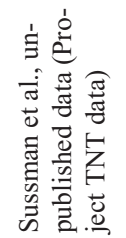

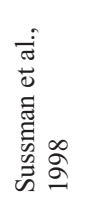
बे
$\frac{\pi}{0}$
$\frac{0}{0}$
$\frac{1}{N}$ 


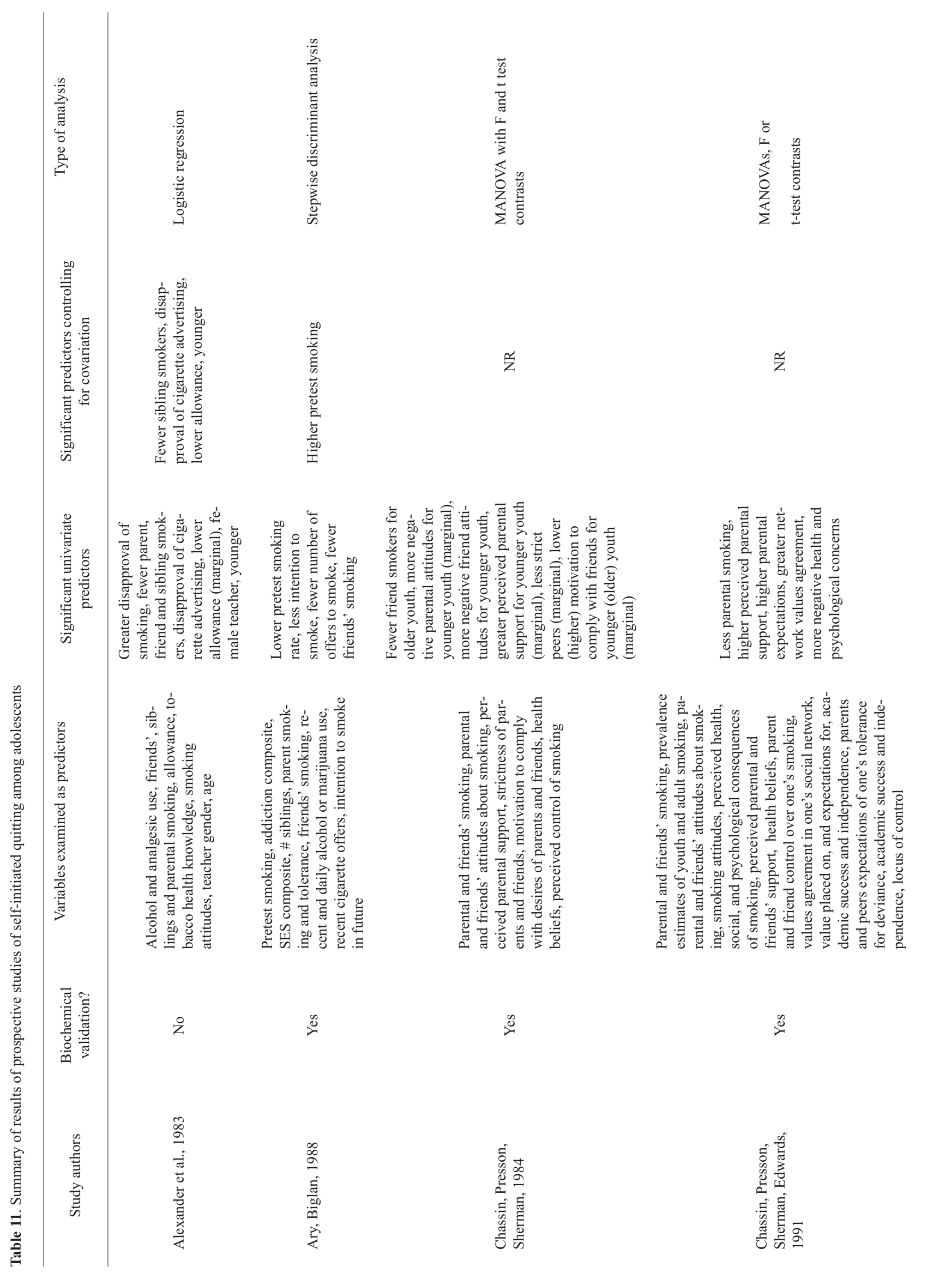



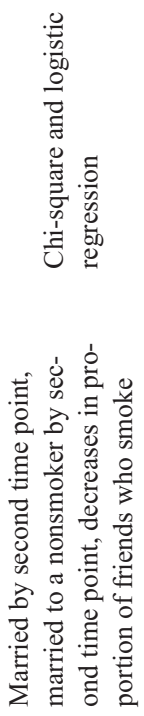

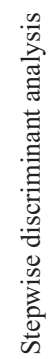

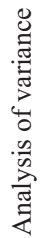

苞

艺

岁

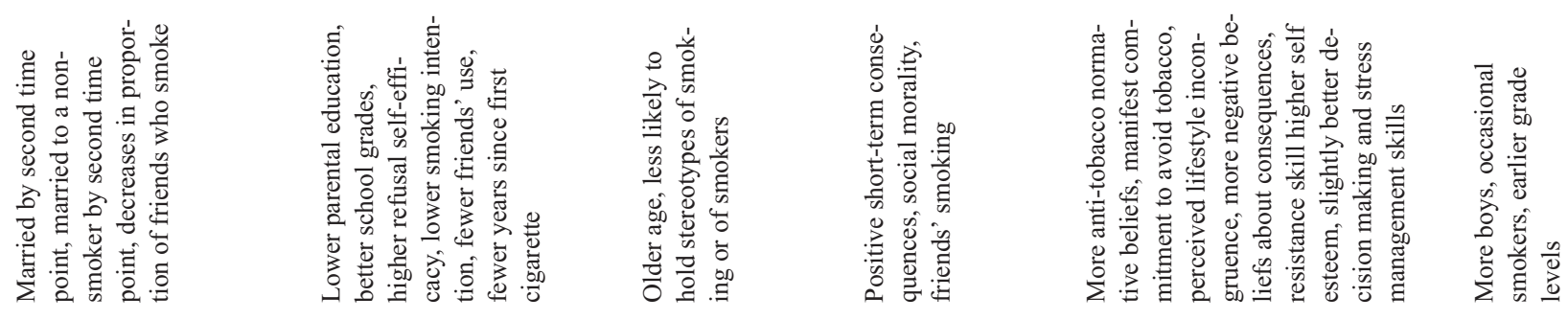

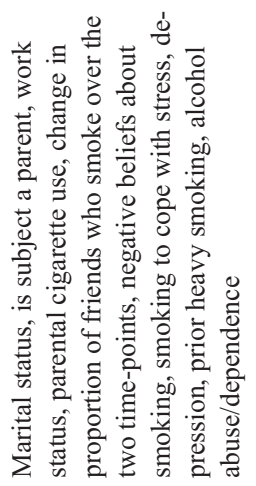

z

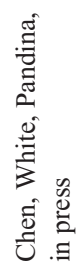

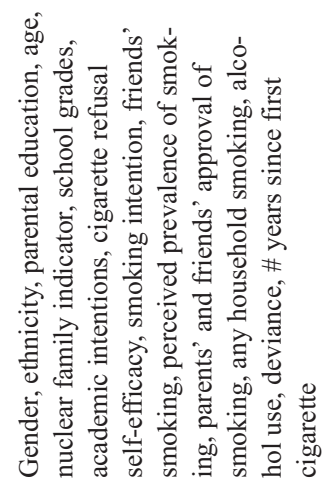

ֻ

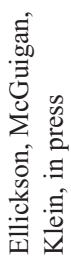

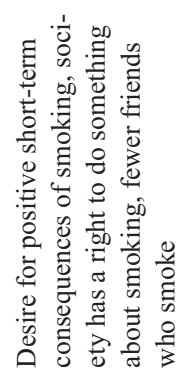

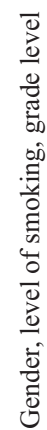

ž そ̊

z̊ z
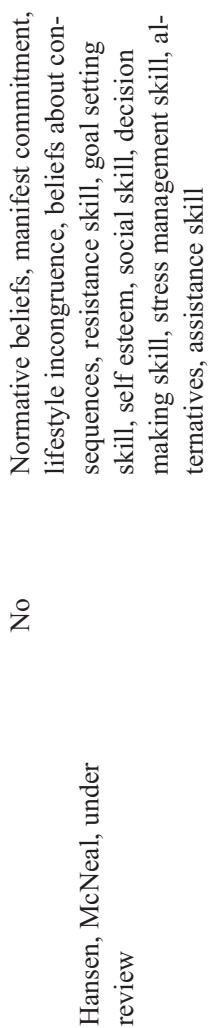


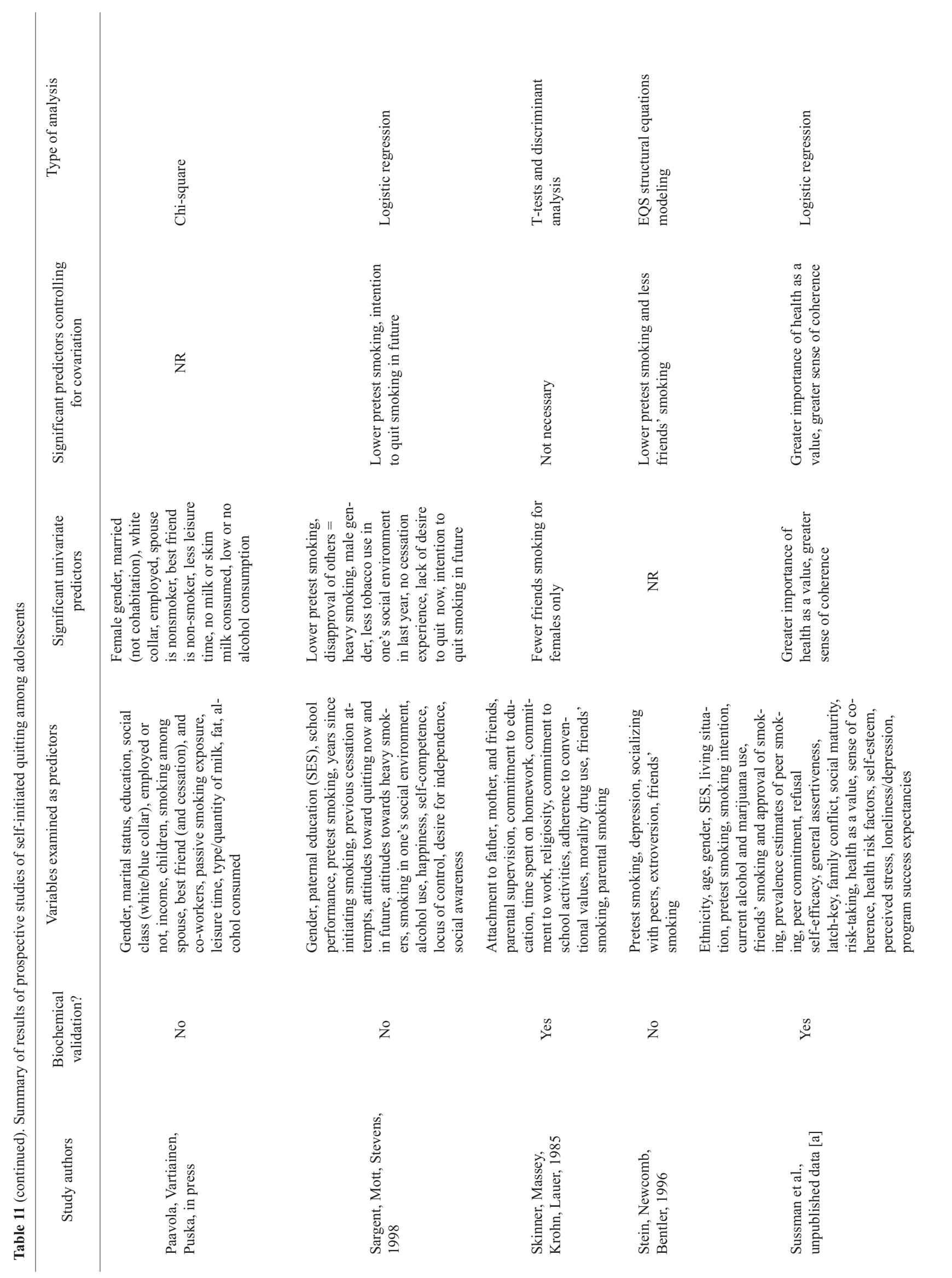




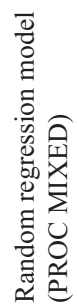

0
$\frac{0}{0}$
0
0
0
0
0
0
.02
00
0
0
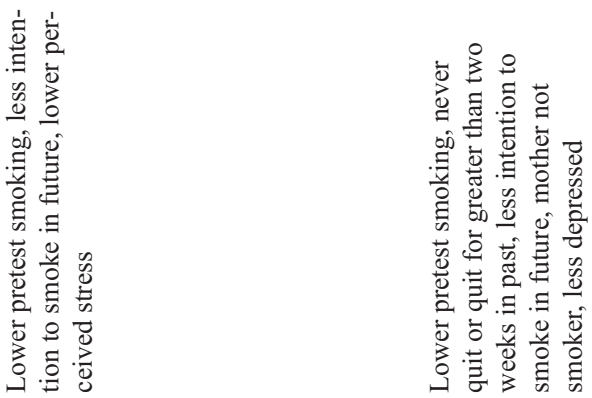

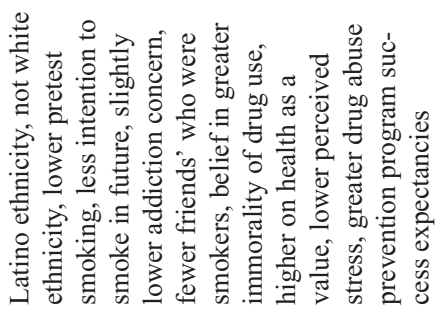
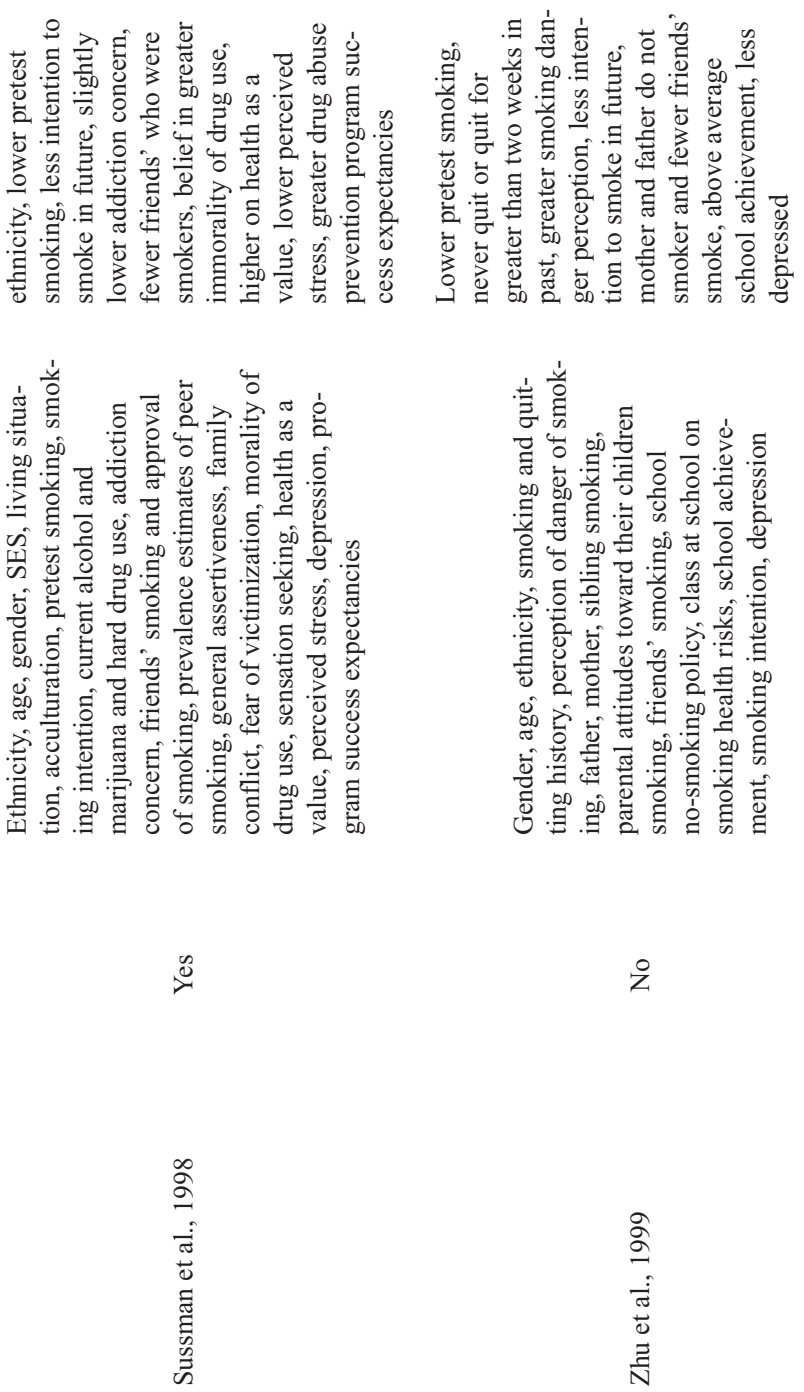

之̊

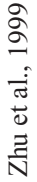


sessions were delivered (23 programs), the follow-up quit-rate was $15 \%$ and the percentage reduction was $30 \%$ (based on 16 program data points). Where nine or more sessions were delivered (ranged from nine to 20 sessions; nine programs), the follow-up quit rate was $20 \%$ (based on eight program data points) and the percentage reduction was $46 \%$ (based on seven program data points). Clearly, number of sessions is related to program success for teen cessation.

Strength of Evidence of Effectiveness Provided by Studies. A table is provided that assesses the standard (quality) of evidence of effectiveness of the 34 studies that found the highest quit-rates among all 66 studies (Table 9). Evidence of effectiveness criteria are used to suggest whether or not outcomes found in a set or subset of studies provides strong, sufficient, or insufficient evidence to infer a "real" effect. This set of criteria was established by the Centers for Disease Control and is used by various research agencies to provide a first step in the process of identifying evidence-based programming (see [93]; Appendix B, Table 2).

A "strong" quality of evidence of effectiveness for a set of studies is one in which the studies were executed reasonable well. Also, the design at least includes multiple pretest or posttest measurements (if not also a comparison group), there are multiple studies used to make an inference, these studies provide consistent information, and a clinically meaningful effect size is achieved. A "sufficient" quality of evidence of effectiveness is achieved generally when the set of studies lacks one of these features. "Expert opinion" can be used as a means to judge the quality of the evidence; however, this is a relatively weak means of inference. Finally, evidence of effectiveness may be considered "insufficient." For example, if there is a great deal of difficulty with study execution (e.g., low reach, retention, follow-up), if the design suitability tends to include single pre or posttest measurements and no comparison group, if only one study is available among group of studies being examined, and if a very small effect is achieved, the evidence that a type of study is effective would be "insufficient."

Only programs that achieved a follow-up quit rate of at least $10 \%$ were included (34 of 66 studies) in the Table. Quit-rates shown in the Table are divided up between 10-12\% and $13+\%$. The average sample sizes per cell in the design are divided into greater than 20,30 , and 40 subjects per cell. The design is experimental (E), quasi-Experimental (QE), or single group (SG). In addition, denotation of a community trial (C) was used to indicate plausible/appropriate use of a SG design (see [93]). Use of an immediate outcome proxy, which is not ideal, for a follow-up outcome is indicated by "IM." "DIFF" indicates whether or not and how much of a difference in quit-rate was observed between a program and control group. A reach of $24+\%$ and retention of $49+\%$ also are identified. If follow-up rate is $49+\%$, then it too could be used as a proxy for retention rate.

Overall, the evidence of effectiveness of teen cessation programs compared to no or minimal programming is strong. The evidence of relative effectiveness for motivation enhanced and contingency-based programs are strong as well as is the evidence for use of a classroom modality. There were enough well conducted studies to make these inferences. However, the quality of the execution of these studies does vary greatly. As examples, the Ary et al. [31], Sussman, Dent, \& Stacy [58], and Sussman, Dent, \& Lichtman [57] programs have sample sizes greater than 40 subjects per cell, use a comparison group, do not use a proxy measure, provide a program group-control group difference score, have reach and retention rates above $23 \%$ and $48 \%$, respectively, and achieve quit rates greater than $12 \%$. Also, significant differences are reported between the control and program groups. The Charlton study [41] did not have a high retention, the Colby et al. [52] and Greenberg and Deputat [89] studies included a small sample size per cell. Further, the Digiusto [23] and Vartianen et al. [65] studies did not have a high reach, and the Glasgow et al. [17] study achieved only a $10 \%$ quit rate. The Murray, Prokhorov, \& Harty [71] study, while achieving a $2.3 \%$ quit rate, found only a $0.1 \%$ quit rate in the control condition. (Since 450 light smokers were included in this study, apparently five people quit due to the program.)

Aside from these 34 studies, no other study achieved a quit-rate above $7 \%$, or provided evidence against a control condition of a program effect, among the 66 programs. The criteria used are not the same as "Best Practice" criteria [see 93]. "Best Practice" criteria provide criteria to compare teen cessation studies against each other. Within the present pool of 66 studies, no teen cessation study would show a strong or medium level of evidence of being a Best Practice (which demands multiple trials or case studies of a program). It would also be difficult to establish practicality criteria. That is, based on the research reports, it is difficult to know whether these programs vary in difficulty of facilitator training, implementation inconvenience, or cost of implementation. One can only "eyeball" these studies and get an idea on relative effectiveness of the programs that may be represented by them.

Outcomes As a Function of Gender and Ethnicity. Among the 34 studies with the highest program quit-rates (i.e., greater than 9\%; see Table 9), 28 reported gender and, of those, 11 were composed of greater than $50 \%$ female, 13 were composed of greater than $50 \%$ male, and 4 were distributed evenly. In addition, 17 of these studies reported ethnicity and, of those, 13 were majority white and four were majority non-white. Thus, study results did not appear to vary systematically by gender and ethnicity (regarding the latter, approximately $71 \%$ of all studies were majority white). However, these data are too sparse to make any strong claims in this regard. More complete data collection and/or data reporting is needed in teen tobacco use cessation work in order to assess varying needs and responses of different groups of youth.

Outcomes As a Function of Age Range. Among the 34 studies with the highest program quit-rates, all reported age range. The age distribution varied from 11 to 24 years old, and modal ages were 16 years old ( $n=26$ studies), $17(n=23$ studies), $15(\mathrm{n}=22$ studies), 18 ( $\mathrm{n}=20$ studies $), 14(\mathrm{n}=19$ 
studies), $13(\mathrm{n}=8$ studies), $19(\mathrm{n}=6$ studies), and $12(\mathrm{n}=5$ studies). Comparing the modal ages in this high-performance sub-sample ( $\mathrm{n}=34$ studies) with the full sample ( $\mathrm{n}=66$ studies) suggests no meaningfully significant variation in outcomes as a function of age. The sub-sample ranking matches the full sample ranking. As examples, the modal ages of 16, 17,15 , and 18 years of age are represented among $82 \%$ and $76 \%, 70 \%$ and $67 \%, 77 \%$ and $65 \%$, and $70 \%$ and $59 \%$, of the full sample and sub-sample, respectively.

Outcomes As a Function of Baseline Tobacco Use. Among the 34 studies with the highest program quit-rates, 28 reported baseline tobacco use. The mean baseline tobacco use across these studies was estimated at 8.0 cigarettes per day. Looking at only the studies that reported a quit-rate greater than $12 \%$, the mean baseline tobacco use was estimated at 7.5 cigarettes per day (data was available on 23 studies). Since overall baseline sample tobacco use was an estimated mean of 8.4 cigarettes per day, it would appear that program success is not a function of baseline tobacco use in this set of studies.

\section{SELF-INITIATED CESSATION STUDIES}

The second part of this review pertains to all known prospective self-initiated cessation survey studies. These studies involve the collection of survey data from teen tobacco users at two or more time-points. Some baseline tobacco users report quitting at a later time-point. These ex-tobacco users are considered to exhibit "self-initiated" cessation; that is, they appeared to quit on their own without involvement in a formal quit-effort. By examining other variables measured at baseline, one can uncover predictors of later quitting (versus not quitting).

\section{Selection Criteria}

Only prospective studies were included in this review (i.e., the same cohort of subjects are tracked over time). Ten studies were selected from a previous review-and-empirical study of self-initiated quitting [1,95-102]. Another three studies were uncovered by a search of the literature [103-105], and 4 studies provided by research colleagues [106-109].

\section{Study Methods}

These studies involved administration of surveys at two time-points. In these studies, retention generally is over $80 \%$, and drops to $70 \%$ over longer time lags (i.e., several years after baseline). Exceptions include that attrition (i.e., percentage of subjects who were measured at baseline but who were not measured at the second time-point) was $60 \%$ in the Stein, Newcomb, \& Bentler study [98]; 33\% in Sussman et al., for a high risk sample [1]; and 33\% in Ary \& Biglan [102]. Attrition analyses were performed in these studies indicating very few differences between those measured at two time-points and those measured only at baseline. Time lag between measurement points ranged from one month to 13 years (Table 10). Specifically, five studies provided a one year lag, two studies each provided a two year, five year, or seven year lag, and one study each provided a one month, three months, two year, four year, 12 year, or 13 year lag (the mean duration is 3.9 years). One study collected data in the 1960 s, four collected data in the 1970s, 11 collected data in the 1980s, seven collected data in the 1990s, and one study collected data after the Year 2000.

\section{Target Population}

Data was collected in an overall age range extending from approximately 12 years old to 28 years old (Table 10). Baseline age ranged from 12 to 16 years old in all but one study (in Green [103], baseline age ranged from 12 to 18 years old). Gender was reported in 16 studies and was predominantly female in six studies, predominantly male in three studies, and an even split in the remaining seven studies. Ethnicity was reported in only nine studies, and the majority was white in eight of the nine studies (mean $=78.2 \%$ white; the exception was the Sussman et al. study [1]). Number of baseline smokers ranged from 64 to 2151 .

\section{Self-initiated Study Quit Rates}

Long-term self-initiated quit rates of the 17 available prospective studies averaged $31.8 \%$ (range $=15-61 \% ; 10$ of 17 studies ranged $10 \%$ around mean; 14 of 17 studies ranged $15 \%$ around mean). Three outlier study data points, $15 \%$, $51 \%$, and $61 \%$ - which defined smoking as "smoked once or twice," "in last year," and "ever tried" - did not measure cessation from regular use. In 6 of the studies youth had been exposed to some type of drug health programming, but not cessation material.

Difference in Quit-Rates: Program Studies versus Self-initiated Quit Studies. The difference in cessation rates between the program (7.2\%) and self-initiated cessation (31.8\%) studies may be explained in part due to baseline level of tobacco use. In the program studies, these were fairly heavy smokers. An approximate grand mean of 8.4 cigarettes per day is reported. In 16 of 17 self-initiated quitting studies that reported it, baseline smoking was defined as "ever tried" or "once or twice" in two studies. It was identified as "in the last year" in one study, at least "occasionally" in one study, "in the last 30 days" in seven studies, and "in the last seven days" in two studies. It was identified as greater than once per day in two studies; and "identify as a smoker" (a mean of seven cigarettes per day) in one study. Average smoking in the self-initiating quitting studies was approximately 0.6 cigarettes per day (having smoked once or twice is coded as .005 cigarettes per day, once in last 30 days is coded as .033 cigarettes per day, and once in last seven days is coded as .14, cigarettes per day). Clearly there was much greater variation of definition of smoking in the self-initiated quitting studies and the sample was comprised of much lighter smokers (i.e., 0.6 versus 8.4 cigarettes per day in the intervention studies). In fact, extrapolated across these mean values, for every cigarette per day increase (from 0.6 to 8.4), the percentage quit rate goes down approximately $3.2 \%$ (from 31.8 to 7.2 ). One could use this 
type of index to estimate a long-term naturally occurring quit rate among a cohort, although the variation in data across studies is great. Six self-initiated quitting studies are composed of primarily (at least 55\%) daily smokers at baseline. Over a mean of 2.8 years, approximately $24 \%$ of these smokers quit. Extrapolating from this index, mean tobacco use would be approximately 2.6 cigarettes per day for these relatively heavy smokers, which does seem to fit the data (Table 11).

\section{Predictors of Quitting}

Across these 17 studies, 41 significant univariate predictors were found, as is shown in Table 12. No consistent demographic trends were found. Univariate predictors in three or more studies include having fewer friends who smoke, intending not to smoke in the future, having less duration of smoking experience, having parents or siblings who do not smoke, and believing in the appropriateness of social controls against smoking. Predictors in two studies include not viewing smoking as having definite social images that are realized, holding negative outcome expectancies of smoking, and disapproving of smoking in others. Other predictors in these two studies included having greater refusal assertion skill, having higher grades, settling down (getting married, having a spouse who doesn't smoke, obtaining a job), and perceiving smoking as socially unacceptable.

Controlling for Covariation Among Predictors. Seven studies did not control for co-variation among predictors. Of those 10 studies that did engage in such analyses, generally discriminant analysis or logistic regression was used. Variables found to remain significant after controlling for co-variation with other predictors included lower pretest smoking (five studies), fewer friends who smoke (four studies), lower intention to smoke in the future (three studies), and believing in the appropriateness of social controls against smoking (two studies). Other variables found to remain significant include having parents or siblings who do not smoke (two studies), having less duration of smoking experience (two studies), and not viewing smoking as having definite social images that are realized (one study). Still other variables found to remain significant include less allowance (perhaps indicating less capacity to buy cigarettes; one study), higher sense of coherence about life (one study), higher importance placed on health as a value (one study), lower perceived stress (one study), and less depression (one study). Finally, settling down was another predictor that remained significant (i.e., showing covariation with getting married between measurement waves, married to a nonsmokers; one study).

In general, the best predictors include living in a social milieu that is composed of fewer smokers (more non-smokers), intending not to smoke in the future, lower pretest smoking and less experience with smoking, belief that society should step in to place controls on smoking, perceiving smoking as negative behavior, and feeling relatively hopeful about life. Thus, social variables (this may include settling down with a nonsmoker and beginning to take on a job), intent, dependence, attitudes against smoking, and believing in a good future, perhaps, are key predictors of quitting.

\section{GENERAL DISCUSSION}

This paper provides the most comprehensive review to date of teen tobacco use cessation; 66 programs and 17 prospective self-initiated cessation studies were included. Detailed information from any program that provided a quit session and some data collection was included among the program studies. Also, a time lag as brief as three months was permitted for inclusion in the survey studies. Sufficient data were collected to provide at least a reasonable descriptive presentation of variables relevant to teen tobacco use cessation. For the program studies, which included heavier tobacco users than the self-initiated cessation studies, the overall control-group mean quit-rate was approximately $7 \%$ and the overall program cessation mean was $12 \%$. Based on these data, and available studies that provided direct program-control group comparisons, there is strong evidence that teen cessation programs are more effective than doing nothing or little among those tobacco users who might attend such programs. Regarding percentage consumption reduction findings, however, there are too few studies to make any strong inferences, although it would appear that there is sufficient evidence to state that cessation programs do increase percentage reduction relative to no or little programming.

Above the grand program cessation mean of $12 \%$ are the motivation enhancement and contingency-based reinforcement theory-based programs (among eight theories). Programs that involve manipulation of intrinsic or extrinsic motivation do the best at changing behavior over a three to 12 month follow-up period.

Regarding modalities of cessation, classroom programs do the best (17\% quit-rate). Three expert system (computer-type) programs showed promise (13\% quit-rate). Finally, school-based clinics showed promise $(12 \%, \mathrm{n}=18)$. In addition, it appears that program material applied more intensely (i.e., number of sessions) produces higher cessation rates. Cessation rates did not differ as a function of available data on gender, ethnicity, age, or baseline tobacco use.

It is surprising that supply reduction theory studies failed to find quit rate effects examined over multiple studies. In theory, such programs could be applied to very large numbers of youth, and even if effects were small could elicit cessation in large absolute numbers of youth. Yet, the mean quit rate was $0 \%$. Possibly, new state-wide supply reduction efforts will indicate other findings than those shown here. One can't argue that supply reduction cessation efforts should not continue. However, exactly how these efforts can achieve cessation effects needs further investigation. Perhaps, monopolization of life contexts is needed to remove youth from opportunities for continued use [74]. On the other hand, one may argue that different types of approaches are needed to examine supply 
reduction effects on tobacco consumption. For example, Tauras \& Chaloupka [110] used sequential longitudinal data from the Monitoring the Future Surveys, augmented with cigarette price and policy related measures to estimate smoking cessation equations among young adults (mean age $=23$ years). They found that a $10 \%$ increase in prices are likely to lead to an $11-12 \%$ increase in quit rates among young male and female adults. Possibly, use of this type of methodology will reveal similar price elasticity effects on regular teen smokers, though such work is yet to be completed.

Regarding the self-initiated quit studies, behavior that seems directed away from smoking (living in a social milieu that is composed of fewer smokers, intending not to smoke in the future) is one key to cessation. Less nicotine or psychological dependence on smoking seems to be another key to youth cessation (lower pretest smoking and less experience with smoking). Anti-tobacco beliefs (e.g., that society should step in to place controls on smoking, perceiving smoking as negative behavior) also are keys to quitting. Finally, having the fortitude to maintain a quit-attempt is important (e.g., feeling relatively hopeful about life). Motivation enhancement, social skills provision, combating dependence, and achieving social support from nonsmokers are important theoretical variables that might be considered for programming. Programs that include these aspects do appear to work relatively well.

Key variables relevant to the quitting process may include gaining access and support of a context, structuring the context of programming for youth, motivating quit attempts and reducing ambivalence about quitting, making programming as enjoyable as possible, and helping youth to sustain a quit attempt (e.g., providing ongoing support during the acute withdrawal period). First, to be able to bring in the best programming possible and to facilitate access to participants, a context needs to support cessation efforts. Relevant gatekeepers can provide material support and encourage support of other staff in the same context. Certainly, inclusion of extrinsic motivators (e.g., release time) can be managed best by gatekeepers. Second, one may conjecture that programming should be tailored to the development and the lifestyles of teens. Adults are relatively likely to structure their own lives (e.g., keep careful records of their behaviors, make meeting appointments), and engage in higher-order thinking tasks (e.g., determining what "type" of smoker one is) [111]. Placed into quit-programs, the efficacy of these strategies among teens in not clear. Also, tobacco use among adults generally is at a more consistent and heavier level than teens. While use of pharmacological adjuncts are recommended for adults [3], so little work in this arena has been completed with youth that not much confidence can be placed into suggestions of the usefulness or uselessness of alternative nicotine delivery products for them. It is clear that while highly addicted youth can benefit from programming, they are less likely to quit tobacco use than are less physically addicted youth [112], and may therefore require more intensive interventions (as was recently shown in the data of Sussman, Dent,
\& Lichtman [57]). Some means of assisting more physically dependent youth still needs to be developed. Potentially, inpatient stays to quit tobacco might be helpful for youth, as has been completed among adults at the Mayo Clinic (the current work of R. Hurt and colleagues).

Third, programming needs to motivate quitting now rather than waiting until the future. All tobacco users should be welcome in a program, no matter what their initial stage of change is. Motivational material is likely to be helpful for most tobacco-using youth. Awareness of the changes that gradually occur as a function of smoking (e.g., increased stress, decreased mood) and quitting (e.g., decreased stress, improved mood) need instruction, along with means to help youth overcome ambivalence toward quitting $[57,112]$.

Fourth, programming should be a fun as possible, involving games, dramatizations, and use of alternative medicine concepts. Youth will want to remain in a program that is interesting. Finally, means to support sustained quit-efforts is needed. Youth need the support of adults in multiple contexts to give them some flexibility during early quitting. Possibly, youth need to learn new social life skills so that they can reach out for the assistance they need (e.g., general conversation skills, how to use the yellow pages, knowledge of community organizations). If one was to try to coin a new theory with these steps, perhaps a "motivation, developmental tailoring, resource acquisition follow-through" model of cessation would be a possible name.

\section{Limitations}

There are many limitations with the presentation of these data. First, several statistical means are presented without sufficient consideration of the distribution around those means. Thus, some apparent differences may not be significantly different. Provision of descriptive distributions (e.g., of control group quit-rates) does provide an indication that some differences (e.g., between program cessation and control group cessation) is clinically significant, and would be statistically significant if such methods were applied. However, it would be preferable to employ more sophisticated methods in continued work with these data. For example, use of critical values could indicate which of the theories or modalities are significantly better than the others. Also, use of multivariate methods may be able to provide some insight into the maximal combination of theory with modality for highest quit-rates.

Second, the value of the analysis is limited by the quality of the data. Numerous aggregated estimates across studies needed to be calculated to make comparisons within studies. It is much wiser to pool comparisons first made within studies. For example, an effect size, comparing the difference of a program condition to a control condition within one study should be standardized and pooled across studies to create an average effect size [e.g. 91]. This approach is not possible with so many single-subject design studies and so many missing data points. In other words, it is difficult to conduct a meta-analysis on these cessation programs, though it could 
Table 12. Significant univariate predictors considered across all studies grouped by type

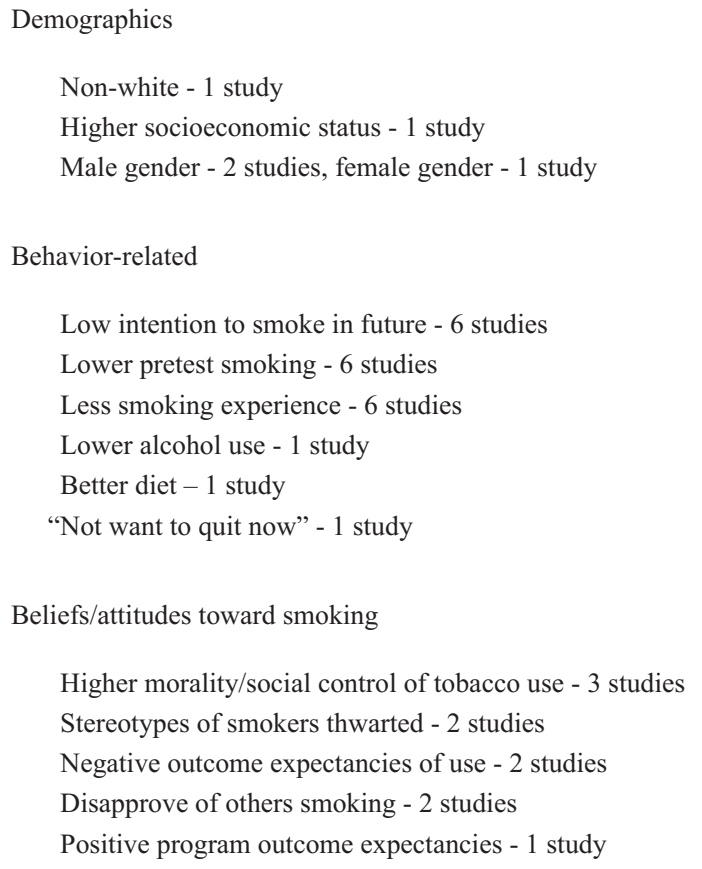

Lifestyle perceptions

High importance on health as a value -2 studies

High sense of coherence - 1 study

Perceived lifestyle incongruence - 1 study

\author{
Bonding opportunities \\ Higher grades -2 studies \\ Got married - 2 studies \\ Parental support - 2 studies \\ Higher parental expectancies for child - 1 study \\ Less allowance - 1 study \\ Less leisure time - 1 study \\ Less strict peers - 1 study \\ Network values agreement - 1 study \\ Less parental education - 1 study
}

Psychology

\author{
Less depressed - 1 study \\ Less perceived stress - 1 study \\ Self-concern - 1 study greater, 1 lower
}

Perceived social

Fewer friends smoke - 12 studies No parent/sibling smoking - 4 studies Lower social acceptability - 2 studies Spouse is a non-smoker - 2 studies Parent don't like smoking - 1 study Fewer offers to smoke - 1 study

Life skills

Greater refusal assertion skill - 2 studies

Higher self-esteem - 1 study

Better decision making skills - 1 study

Better stress management skills - 1 study

Directionality was aligned such that these predictors showed higher quit-rates. Each entry indicates number of studies that found this variable to be a significant predictor.

potentially provide more statistical information about precisely what works and what does not work. Only 12 and 24 studies, respectively, provided direct program-control comparisons. Thus, an absolute reduction in risk statistic also was not calculated. The use of single group designs and comparison to an overall quit rate statistic is speculative, and this important limitation needs correction through future studies that provide control groups measured concurrently with program groups.

There are many scattered areas of missing data. Ethnicity is not described in many of the studies. In studies that do describe ethnicity, a majority white sample is described. Thus, collection of ethnicity data should become a regular process in these studies, and research needs to be completed in areas with higher racial minority concentrations to assess generalizability of programming to different ethnic groups. Percentage reduction statistics are not commonly used. Thus, it is not possible to assess the totality of impact a program may have on teen tobacco use. A standard definition of baseline smoking and quitting is not used, and in several studies quitting is not measured over at least a one-week duration. Thus, it is difficult to compare studies, and the meaningfulness of cessation in several studies is suspect.

There are also several types of data that are not collected in most or all of these studies. These include the measurement of different types of tobacco use, effects of programming on other drug use, level of nicotine dependence and cessation 
(aside from level of pretest tobacco use), duration of smoking and cessation, and patterns of smoking and quitting among youth (i.e., across days). These other types of missing data also include provider characteristics and cessation, or matching of provider characteristics with different types of tobacco users, and issues related to cost and feasibility of implementation. Also included should be assessment of the effects of different social contexts on effectiveness of programming, measurement of mediation of program effects, and measurement of many psychosocial moderators of program effects. These additional pieces of information are needed to better understand teen tobacco use cessation.

Very recently, this review was re-examined by a team of 35 teen tobacco use cessation researchers and practitioners, sponsored by the American Legacy Foundation, Canadian Tobacco Control Research Initiative, Centers for Disease Control and Prevention, and National Cancer Institute ("Youth Tobacco Cessation Collaborative Best Practices Workshop"). The results will be presented in a guide entitled "Youth tobacco use cessation: A guide for making decision to help youth quit." These reviewers decided not to examine percentage reduction information, and made some different theoretical distinctions. In general, however, this re-analysis led to the same conclusions. There are some promising approaches as summarized herein. However, new research is needed including use of more rigorous designs.

\section{The Future}

In 1982, Cheryl Perry wrote on the importance of developing teen cessation programming [11]. Anecdotally, many researchers and practitioners may have assumed that youth would not quit smoking until they became adults and had more reasons to quit. Many researchers were surprised to learn that youth became readily addicted to tobacco and had made several previous attempts to quit. Still, skepticism about youth cessation was based on early unsuccessful experiences.

In some of these experiences, a treatment provider acquired a quit-manual, placed a simple notice in a school or other setting, and then was surprised that only three youth showed up to the program and only one quit. There are probably numerous efforts "out there" that are not contained in this report, which relate such experiences. After more rigorous recruitment strategies were employed, more youth showed up for programming. Still, quit-rates were considered relatively low. Indeed, they are much lower than adult clinic programs, but are as high as adult minimal intervention programs [92].

Once the realization was made that youth prevention programs did not work for everyone, or that effects tended to decay, a renewed interest was gained in the promise of teen cessation programming $[6,112]$. The numbers of programs being researched and implemented has increased dramatically over the last 10 years. However, the technology for measuring older teen's smoking and dependence, defining cessation, and exploring various avenues of cessation assistance (e.g., use of alternative nicotine products) is brand new territory. This review is only able to summarize studies that have been completed thus far. There are many more studies currently in development or in progress (e.g., there currently are 19 teen tobacco use cessation projects underway that are being funded by the National Cancer Institute). Much more information will be learned over the next 10 years. In this time, more complete data will be collected, replication studies will be conducted, better summary analyses will be completed, and a much better understanding of teen cessation will be gained.

\section{ACKNOWLEDGMENT}

This manuscript was supported by grants from the California Tobacco-Related Disease Research Program (6RT-0182 and 9HT-3201) awarded to Drs. Sussman and Dent, and from the National Institute on Drug Abuse (DA07601) awarded to Drs. Sussman, Stacy, and Dent, and by a contract awarded to Dr. Sussman by the Canadian Tobacco Control Research Initiative (CTCRI).

\section{REFERENCES}

1. Sussman S, Dent CW, Severson HH, Burton D, Flay BR. Self-initiated quitting among adolescent smokers. Preventive Medicine 1998; 27: A19-A28.

2. U.S. Department of Health \& Human Services (US DHHS). Preventing tobacco use among young people: A Report of the Surgeon General. (DHHS Publication No. S/N 017-001-00491-0). Washington, D.C.: Public Health Service, 1994.

3. U.S. Department of Health \& Human Services (US DHHS). Reducing tobacco use: A Report of the Surgeon General. Atlanta, Georgia: Office on Smoking and Health, 2000.

4. Dwyer JH, Rieger-Ndakorerwa GE, Semmer NK, Fuchs R, Lippert $\mathrm{P}$. Low level cigarette smoking and longitudinal change in serum cholesterol among adolescents. Journal of the American Medical Association 1988; 259: 2857-2862.

5. Burton D. Tobacco cessation programs for adolescents. In: Richmond R, editor. Interventions for Smokers: An international Perspective. Baltimore, MD: Williams \& Wilkins, 1994.

6. CDC. Youth tobacco use cessation meeting. Centers for Disease Control and Prevention. Atlanta, Georgia: Division of Adolescent and School Health, 1997

7. Lampkin L. "Meet It Head On" Evaluation report. American Medical Association technical report. Chicago: Illinois, 1998.

8. Dino GA, Horn KA, Zedosky L, Monaco K. A positive response to teen smoking: Why N-O-T? National Association of Secondary School Principals 1998; 82: 46-58.

9. Foulds J. Smoking cessation in young people. Should we do more to help young smokers quit? Great Britain: Health Development Agency, 2000.

10. Reddy KS, Townsend J, Kim DH, Foulds J, Vartiainen E, Ferretter I, Iiogu G. Speaking their language: Smoking cessation among adolescents and young people. Scenario-in-the-round at 
the 11th World Conference on Tobacco Or Health, Chicago, August, 2000.

11. U.S. Department of Health \& Human Services (US DHHS). The health consequences of smoking: Cancer. Report of the Surgeon General. (DHHS Publication No. [PHS] 82-50179). Washington, D.C.: Public Health Service, 1982.

12. Sussman S, Lichtman K, Ritt A, Pallonen UE. Effects of thirty-four adolescent tobacco use cessation and prevention trials on regular users of tobacco products. Substance Use \& Misuse 1999; 34: 1469-1503.

13. Librett J. Evaluation of precursors to change: The Ending Nicotine Dependence Program. Unpublished doctoral dissertation. Salt Lake City: University of Utah, 2001.

14. Patten CA, Ames SC, Ebbert JO, Wolter TD, Hurt RD, Gauvin TR. Tobacco use outcomes of adolescents treated clinically for nicotine dependence. Unpublished manuscript, 2001.

15. Popham WJ, Potter LD, Hetrick MA, Muthen LK, Duerr JM, Johnson MD. Effectiveness of the California 1990-1991 tobacco education media campaign. American Journal of Preventive Medicine 1994; 10: 319-26.

16. Etter J-F, Ronchi A, Perneger TV. Short-term impact of a university based smoke free campaign. Journal of Epidemiology and Community Health 1999; 53: 710-715.

17. Glasgow RE, Strychker LA, Eakin EG, Boles SM, Whitlock EP. Concern about weight gain associated with quitting smoking: Prevalence and association with outcome in a sample of young female smokers. Journal of Consulting and Clinical Psychology 1999; 67: 1009-1011.

18. Quinlan KB, Mccaul KD. Matched and mismatched interventions with young adult smokers: Testing a stage theory. Health Psychology 2000; 19: 165-171.

19. Zavela KJ, Harrison LR, Owens S. Factors related to smokeless tobacco cessation in young adults. American Public Health Association 1991; 119: 1-5.

20. Abernathy TJ. Examining youth smoking cessation and relapse prevention: A review of the literature. Toronto: Ontario Tobacco Research Unit 1997 (also Health Canada;

www.hc-sc.gc.ca/hppb/tobaccoreduct...lications/ youth/ relapseprevention/toc.htm).

21. Green LW, Frankish CJ. Smoking cessation: A synthesis of the literature on program effectiveness. British Columbia, Canada: The Institute of Health Promotion Research, University of British Columbia and The British Columbia Ministry of Health and Ministry Responsible for Seniors, 1998.

22. Jerome A. Computer-assisted smoking cessation program for teenage smokers: A preliminary report, 1998.

23. Digiusto E. Pros and cons of cessation interventions for adolescent smokers at school. In: Richmond R. editor. Interventions for Smokers: An International Perspective. Baltimore, Maryland: Williams \& Wilkins, 1994. pp. 107-136.

24. Institute of Medicine (IOM). Growing up tobacco free: Preventing nicotine addiction in youth and adolescents. B.S. Lynch and R.J. Bonnie Editors. Washington, D.C.: National Academy Press, 1994.
25. Pallonen UE. Smoking cessation in adolescence. Unpublished review of the literature, 1987.

26. Campbell DT, Stanley JC. Experimental and quasi-experimental designs for research. Chicago: Rand McNally, 1963.

27. Sussman S, Dent CW, Burton D, Stacy AW, Flay BR. Developing a school based tobacco use prevention and cessation programs. Thousand Oaks, CA: Sage Publications, 1995.

28. Chakravorty BJ. A product substitution approach to adolescent smokeless tobacco cessation. Dissertation Abstracts International, 1992; 53: 2808-9.

29. Eakin E, Severson H, Glasgow, RE. Development and evaluation of a smokeless tobacco cessation program: A pilot study. NCI Monographs 1989; 8: 95-100.

30. Glover ED. Conducting smokeless tobacco cessation clinics. American Journal of Public Health 1986; 76: 207.

31. Ary DV, Biglan A, Glasgow R, Zoref L, Black C, Ochs L, Severson H, Kelly R, Weissman W, Lichtenstein E, Brozovsky P, Wirt R, James L. The efficacy of social-influence prevention programs versus "standard care": Are new initiatives needed? Journal of Behavioral Medicine 1990; 13: 281-296.

32. Beaglehole R, Brough D, Harding W, Eyles E. A controlled smoking intervention programme in secondary schools. New Zealand Medical Journal 1978; 87: 278-280.

33. Horswell L, Horton SA. Telling our story: "PITS"-Pack In Those Smokes: A teen support group quit smoking program. A report presented to the Community Action Initiatives Program, Tobacco Demand Reduction Strategy. Ottawa: Health Canada, 1997.

34. Jason LA, Mollica M, Ferrone L. Evaluating an early secondary smoking prevention intervention. Preventive Medicine 1982; 11 : 96-102.

35. Johnson CA, Hansen WB, Collins LM, Graham JW. High-school smoking prevention: Results of a three-year longitudinal study. Journal Behavioral Medicine 1986; 9: 439-451.

36. Killen JD, Telch MJ, Robinson TN, Maccoby N, Taylor CB, Farquhar JW. Cardiovascular disease risk reduction for tenth graders: A multiple-factor school-based approach. Journal of the American Medical Association 1988; 260: 1728-1733.

37. Perry C, Killen J, Telch M, Slinkard LA, Danaher BG. Modifying smoking behavior of teenagers: A school-based intervention. American Journal of Public Health 1980; 70: 722-727.

38. Perry CL, Telch MJ, Killen J, Burke A, Maccoby N. High school smoking prevention: The relative efficacy of varied treatments and instructors. Adolescence 1983; 18: 561-566.

39. Peterson AJ, Clark AW. Using group decision to reduce adolescent girls' smoking. Psychological Reports 1986; 58: 179-185.

40. Townsend J, Wilkes H, Haines A, Jarvis M. Adolescent smokers seen in general practice: Health, lifestyle, physical measurements, and response to antismoking advice. British Medical Journal 1991; 303: 947-950.

41. Charlton A. Smoking cessation help for young people: the process observed in two case studies. Health Education Research 1992; 7: 249-257.

42. Cinnomin D, Sussman S. Cessation clinic pilot study at a continuation high school. Unpublished data based on the Master's 
Thesis of the first author at California Lutheran University, Los Angeles, CA, 1992. Summarized in Sussman et al. Developing school-based prevention and cessation programs. 1995.

43. Dino GA, Horn KA, Goldcamp J, Massey CJ, Maniar SD, Fernandes A. State-wide demonstration of Not On Tobacco: A gender-sensitive teen smoking cessation program. Journal of the School of Nursing. In press.

44. Horn K, Dino G, Gao X, Momani A. Feasibility evaluation of Not On Tobacco: the ALA's new stop smoking program for adolescents. Health Education 1999; 99: 192-206.

45. Hotte A, Ellis E, Lindsay L, Mcculloch R, Welch L, Meloche A. Dissemination and evaluation of the Quit-4-Life cessation program for teenagers in Ottawa-Carleton high schools. A report presented to the Community Action Initiatives Program, Tobacco Demand Reduction Strategy. Ottawa: Health Canada, 1997.

46. Lotecka L, Macwhinney M. Enhancing decision behavior in high school "smokers". The International Journal of the Addictions 1983; 18: 479-490.

47. Patterson C. Junior high stop smoking groups. The School Counselor 1984; 31: 480-487.

48. Peters L. An evaluation of the Quit 4 Life smoking-cessation program. Ottawa: Health Canada, 1995.

49. Prince F. The relative effectiveness of a peer-led and adult-led smoking intervention program. Adolescence 1995, 30: 187-194.

50. St. Pierre RW, Shute R, Jaycox S. Youth helping youth: a behavioral approach to the self-control of smoking. Health Education 1983; Jan/Feb: 28-31.

51. Bauman KE, Ennett ST, Foshee VA, Pemberton M, King TS, Koch GG. Influence of a family-directed program on adolescent cigarette and alcohol cessation. Prevention Science 2000; 1: 227-237.

52. Colby SM, Monti PM, Barnett NP, Rohsenow DJ, Weissman K, Spirito RH, Woolard RH, Lewander WJ. Brief motivational interviewing in a hospital setting for adolescent smoking: A preliminary study. Journal of Consulting and Clinical Psychology 1998; 66: 574-578.

53. Eakin EG, Glasgow RE, Whitlock EP, Smith PS. Reaching those most in need: Participation in a planned parenthood smoking cessation program. Annals of Behavioral Medicine 1998; 20: 216-220.

54. Goldberg ME, Gorn GJ. Increasing the involvement of teenage cigarette smokers in antismoking campaigns. Journal of Communication 1982; 32: 75-86.

55. Hafstad A, Aaro LE, Langmark F. Evaluation of an anti-smoking mass media campaign targeting adolescents: the role of affective responses and interpersonal communication. Health Education Research 1996; 11: 29-38.

56. Myers MG, Brown SA, Kelly JF. A smoking intervention for substance abusing adolescents: Outcomes, predictors of cessation attempts, and post-treatment substance use. Journal of Child \& Adolescent Substance Abuse 2000; 9: 77-91.

57. Sussman S, Dent CW, Lichtman KL. Project EX: Outcomes of a teen smoking cessation program. Addictive Behaviors 2001; 26: 425-438.
58. Sussman S, Dent CW, Stacy AW. Project TND: An effective high school-based drug abuse prevention program. American Journal of Health Behavior. In press.

59. Zheng C. Working with Chinese youth on tobacco control. Project EX pilot study in Wuhan. Unpublished manuscript, 2000.

60. Miller WR, Rollnick S. Motivational interviewing: preparing people to change addictive behavior. New York: Guilford Press, 1991.

61. Nezami E, Sussman S, Pentz MA. Motivation in tobacco use cessation research. Substance Use \& Misuse. In press.

62. Baskerville, B., Hotte, A., Dunkley, G. Evaluation of a high school Quit and Win smoking-cessation program. Community Health Research Unit, University of Ottawa, 1993.

63. Corby, E.A., Roll, J.M., Ledgerwood, D.M., Schuster, C.R. Contingency management interventions for treating the substance abuse of adolescents: A feasibility study. Experimental and Clinical Psychopharmacology 2000, 8: 371-376.

64. Matson-Koffman DM, Miller J. The Quit and Win Tobacco Free Project for Teens. National Conference on Chronic Disease Prevention and control, Atlanta, GA, 1995.

65. Vartiainen E, Paavola M, Koski N, Puska P. Quit and Win- Do Not Start and Win: Smoking cessation program for young people. Under review.

66. Weissman W, Glasgow R, Biglan A, Lichtenstein E. Development and preliminary evaluation of a cessation program for adolescent smokers. Psychology of Adolescent Behaviors 1987; 1: 84-91.

67. Curry S, Wagner EH, Gothaus LC. Intrinsic and extrinsic motivation for smoking cessation. Journal of Consulting and Clinical Psychology 1990, 58: 310-316.

68. Pentz MA, Bonnie RJ, Shopland DR. Integrating supply and demand reduction strategies for drug abuse prevention. American Behavioral Scientist 1996; 39: 897-910.

69. Biener L, Aseltine RH, Cohen B, Anderka M. Reactions of adult and teenage smokers to the Massachusetts tobacco tax. American Journal of Public Health 1998; 88: 1389-1391.

70. Kempf J, Stanley A. Impact of tobacco-free policy on recruitment and retention of adolescents in residential substance abuse treatment. Journal of Addictive Diseases 1996; 15: 1-11.

71. Murray DM, Prokhorov AV, Harty KC. Effects of a statewide antismoking campaign on mass media messages and smoking beliefs. Preventive Medicine 1994; 23: 54-60.

72. Forster JL, Murray DM, Wolfson M, Blaine TM, Wagenaar AC, Hennrikus DJ. The effects of community policies to reduce youth access to tobacco. American Journal of Public Health 1998; 88: 1193-1198.

73. Rigotti NA, Difranza JR, Chang YC, Tisdale T, Kemp B, Singer DE. The effect of enforcing tobacco-sales laws on adolescents' access to tobacco and smoking behavior. The New England Journal of Medicine 1997; 337: 1044-1051.

74. Wakefield MA, Chaloupka FJ, Kaufman NJ, Orleans CT, Barker DC, Ruel EE. Effects of restructions on smoking at home, at work, at school, and in public places on teenage smoking: Cross sectional studies. British Medical Journal 2000; 321: 333-337. 
75. Fibkins WL. Combating student tobacco addiction in secondary schools. National Association of Secondary Schools Bulletin 1993; 77: 51-59.

76. Hurt RD, Croghan GA, Beede SC, Wolter TD, Croghan IT, Patten CA. Archives of Pediatrics \& Adolescent Medicine 2000; 154: 31-37.

77. McDonald C, Roberts S, Deeschaemaker N. Intentions to quit smoking in substance-abusing teens exposed to a tobacco program. Journal of Substance Abuse Treatment 2000; 18: 291-308.

78. Myers MG, Brown SA. Smoking and health in substance-abusing adolescents: A two-year follow-up. Pediatrics 1994; 93: 561-566.

79. Skjoldebrand J, Gahnberg L. Tobacco preventive measures by dental care staff. An attempt to reduce the use of tobacco among adolescents. Swedish Dental Journal 1997; 21: 49-54.

80. Smith TA, House RF, Croghan IT, Gauvin TR, Colligan RC, Offord KP, Gomez-Dahl LC, Hurt RD. Nicotine patch therapy in adolescent smokers. Pediatrics 1996; 98: 659-667.

81. Aveyard P, Cheng KK, Almond J, Sherratt E, Lancashire R, Lawrence T, Griffin C, Evans O. Cluster randomised controlled trial of expert system based on the transtheoretical ("stages of change") model for smoking prevention and cessation in schools. British Medical Journal 1999; 319: 948-953.

82. Coleman-Wallace D, Lee JW, Montgomery S, Blix G, Wang DT. Evaluation of developmentally appropriate programs for adolescent tobacco cessation. Journal of School Health 1999; 69: 314-319.

83. Mills D, Ewy BM, Dizon J. Smoking cessation in high school. Health Education 1978; May/June: 5-7.

84. Pallonen UE, Velicher WF, Prochaska JO, Rossi JS, Bellis JM, Tsoh JY, Migneault JP, Smith NF, Prokhorov AV. Computer-based smoking cessation interventions in adolescents: Description, feasibility, and six month follow-up findings. Substance Use \& Misuse 1998; 33: 1-31.

85. Pendell WK. Community intervention. Intervening with teen tobacco users. In: Tobacco Education Group (TEG). Minneapolis, MN: Community Intervention, Inc., 1996.

86. Pallonen UE, Prochaska JO, Velicer WF, Prokhorov AV, Smith NF. Stages of acquisition and cessation for adolescent smoking: An empirical integration. Addictive Behaviors 1998, 23: 303-324.

87. Prochaska JO, Diclemente CC. Stages and process of self-change smoking: Toward an integrative model of change. Journal of Consulting and Clinical Psychology 1983; 51: 390-395.

88. Pallonen U. Computer-assisted youth smoking cessation. Speaker presentation at the Youth Tobacco Use Cessation Meeting. Atlanta, Georgia: Centers for Disease Control and Prevention, Division of Adolescent and School Health, September 1997.

89. Greenberg JS, Deputat Z. Smoking intervention: Comparing three methods in a high school setting. The Journal of School Health 1978; 48: 498-502.

90. Suedfeld P, Landon PB, Pargament R, Epstein YM. An experimental attack on smoking (attitude manipulation in restricted environments, III). The International Journal of the Addictions 1972; 7: 721-733.

91. Tobler NS, Roona MR, Ochshom P, Marshall DG, Streke AV, Stackpole KM. School-based adolescent drug prevention programs: 1998 Meta-analysis. Journal of Primary Prevention 2000; 20: 275-336.

92. Fiori MC, Bailey WC, Cohen SJ., et al. Treating tobacco use and dependence. Clinical Practice Guideline. Rockville, MD: U.S. DHHS. PHS, 2000.

93. Moyer CA, Cameron R, Garcia J. Best practices for complex problems. Ontario: Canadian Tobacco Control Research Initiative. Working draft, 2001.

94. Stacy AW, Flay BR, Sussman S, Brown KS, Santi S, Best JA. Validity of alternative self-report indices of smoking among adolescents. Psychological Assessment: Journal of Consulting and Clinical Psychology 1990; 2: 442-446.

95. Hansen WB, Collins LM, Johnson CA, Graham JW. Self-initiated smoking cessation among high school students. Addictive Behaviors 1985; 10: 265-271.

96. Laoye JA, Cresswell W, Stone EB. A cohort of 12,205 secondary school smokers. Journal of School Health 1972; 42: 47-52.

97. Skinner WF, Massey JL, Krohn MD, Lauer RM. Social influences and constraints in the initiation and cessation of adolescent tobacco use. Journal of Behavioral Medicine 1985; 8: 353-376.

98. Stein JA, Newcomb MD, Bentler PM. Initiation and maintenance of tobacco smoking: Changing personality correlates in adolescence and young adulthood. Journal of Applied Social Psychology 1996; 26: 160-187.

99. Chassin L, Presson CC, Sherman SJ. Cognitive and social influence factors in adolescent smoking cessation. Addictive Behaviors 1984; 9: 383-390.

100.Chassin L, Presson CC, Sherman SJ, Edwards DA. Four pathways to young-adult smoking status: Adolescent social-psychological antecedents in a midwestern community sample. Health Psychology 1991;10: 409-418.

101. Alexander HM, Callcott R, Dobson AJ, Hardes GR, Lloyd DM, O'Connell DL, Leeder SR. Cigarette smoking and drug use in schoolchildren: IV - Factors associated with changes in smoking behavior. International Journal of Epidemiology 1983; 12: 59-65.

102. Ary DV, Biglan A. Longitudinal changes in adolescent cigarette smoking behavior: Onset and cessation. Journal of Behavioral Medicine 1988; 11: 361-382.

103. Green DE. Teenage smoking: Immediate and long-term patterns. Washington, D.C.: U.S. DHEW, 1979. (Cited in U.S. Surgeon General's Report, 1982).

104. Sargent JD, Mott LA, Stevens M. Predictors of smoking cessation in adolescents. Archives of Pediatrics \& Adolescent Medicine 1998; 152:388-393.

105. Zhu SH, Sun J, Billings SC, Choi WS, Malarcher A. Predictors of smoking cessation in U.S. adolescents. American Journal of Preventive Medicine 1999; 16: 202-207.

106. Hansen WB, McNeal RB. Self-initiated cessation from substance use: A longitudinal study of the relationship between 
postulated mediators and quitting. Journal of Drug Issues. Under review.

107. Paavola M., Vartiainen, E., Puska, P. Smoking cessation between teenage years and adulthood. Health Education Research. In press.

108. Chen P-H, White HR, Pandina RJ. Predictors of smoking cessation from adolescence into young adulthood. Addictive Behaviors. In press.

109. Ellickson PL, Mcguigan KA, Klein DJ. Predictors of late-onset smoking and cessation over 10 years. Journal of Adolescent Health. In press.
110. Tauras JA, Chaloupka FJ. Determinants of smoking cessation: An analysis of young adult men and women. Working paper 7262. Cambridge, MA: National Bureau of Economic Research, July 1999

111. Jackson AW, Hornbeck DW. Educating young adolescents. Why we must restructure middle grade schools. American Psychologist 1989; 41: 831-836.

112. Flay BR. Youth tobacco use: Risks, patterns and control. In: C. Tracy Orleans and John Slade Editors. Nicotine Addiction: Principles and Management, 1993. 
